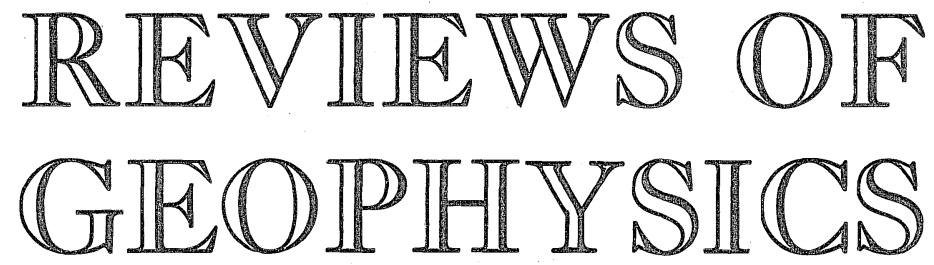

VOLUME 7

NOVEMBER 1969

NUMBER 4

\title{
Equations of State and Crystal Structures of High-Pressure Phases of Shocked Sillicates and Oxides ${ }^{1}$
}

\author{
Thomas J. Ahrens, Don L. Anderson, and A. E. Ringwood ${ }^{2}$ \\ California Institute of Technology, Seismological Laboratory \\ Pasadena, California 91109
}

\begin{abstract}
Shock-wave data are now available for a variety of rocks, minerals, and oxides of geophysical interest in the pressure range appropriate for the lower mantle. These data are analyzed to obtain equation-of-state parameters with emphasis on the shock-induced high-pressure phases. Of twenty-four materials for which Hugoniot data are analyzed, all but $\mathrm{MgO}, \mathrm{Al}_{2} \mathrm{O}_{3}$, and $\mathrm{MnO}_{2}$ undergo at least one shock-induced phase change below $800 \mathrm{~kb}$. Birch-Murnaghan parameters for the raw Hugoniots, metastable Hugoniots, adiabats, and $25^{\circ} \mathrm{C}$ isotherms are obtained for the high-pressure phases. On correcting the raw Hugoniot data for $\mathrm{MgO}$ and $\mathrm{Al}_{2} \mathrm{O}_{3}$ for strength effects, we find that the calculated adiabatic equations of state are in good agreement with recent ultrasonic data. The zero-pressure densities of high-pressure phases are obtained by constraining the adiabats calculated from the Hugoniot data such that the zeropressure densities and the zero-pressure slopes of the adiabats satisfy Anderson's seismic equation of state.

Probable crystallographic structures of the high-pressure phases are inferred from the classical laws of crystal chemistry and, in some cases, from static high-pressure recovery experiments on analog compounds. Shock data for $\mathrm{SiO}_{2}$ (stishovite) indicate that transformation to the fluorite-type structure (observed in $\mathrm{TiO}_{2}$ ) does not take place under shock, at least to $\sim 2000 \mathrm{~kb}$. $\mathrm{Fe}_{2} \mathrm{O}_{3}$ probably transforms to either the perovskite or $\mathrm{B}$ rare earth structure with a zero-pressure density of $5.96 \mathrm{~g} / \mathrm{cm}^{3} . \mathrm{MgAl}_{2} \mathrm{O}_{4}$ (spinel) may transform to the $\mathrm{CaFe}_{2} \mathrm{O}_{4}$ structure with a zero-pressure density of $4.19 \mathrm{~g} / \mathrm{cm}^{3}$.
\end{abstract}

${ }^{1}$ Contribution 1571, Division of Geological Sciences, California Institute of Technology, Pasadena.

2 On leave from Australian National University, Canberra, Australia. 
Feldspars transform to the hollandite structure (density, of $\sim 3.85 \mathrm{~g} / \mathrm{cm}^{3}$ ). Olivine-rich rocks containing greater than $10 \% \mathrm{FeO}$ either disproportionate to the ilmenite and rock salt structure or transform to a new post-spinel polymorph having the $\mathrm{Sr}_{2} \mathrm{PbO}_{4}$ structure. Pyroxenes containing greater than $10 \% \mathrm{FeO}$ probably transform to the ilmenite structure. High-pressure forms of sillimanite and andalusite have calculated densities of 4.00 and $3.95 \mathrm{~g} / \mathrm{cm}^{3}$, respectively. This probably represents disproportionation reaction products, $\mathrm{Al}_{2} \mathrm{O}_{3}+\mathrm{SiO}_{2}$ (stishovite), which would give a density of $4.09 \mathrm{~g} / \mathrm{cm}^{3}$. The Birch-Murnaghan second-order parameter $\xi$ is nearly zero for $\mathrm{MgO}$ and $\mathrm{Al}_{2} \mathrm{O}_{3}$. 0.73 for stishovite, and $\sim 1$ for the high-pressure phases of the olivines and pyroxenes. The values of $K^{\prime}=d K / d P^{\prime}$ are calculated along the Hugoniots and adiabats and are found to decrease at a rate of -0.5 to $-1.6 \mathrm{~cm}^{3} / \mathrm{g}$ when the density is increased either by compression or by iron substitution.

\section{INTRODUCTION}

Birch [1952] suggested that the ferromagnesium silicates undergo a series of phase transformations in the earth's mantle and that below about $1000 \mathrm{~km}$ $(\sim 390 \mathrm{~kb})$ these minerals transform to closely packed crystal structures whose elastic properties are similar to the elastic properties of the closely packed oxides. The discovery by Stishov and Popova [1961] that quartz and coesite could transform to a polymorph having the rutile structure, with the silicon in octahedral coordination, suggested that related transformations could occur in other silicates [see, for example, Ringwood, 1966]. This has stimulated a search by static high pressure researchers for transformations in silicates and analog compounds such as germanates. Although such transformations have been found in germanate pyroxenes and germanate-silicate solid solutions [Ringwood and Seabrook, 1962, 1963], the expected transition pressures in ferromagnesium silicates required for structures in which silicon atoms are octahedrally coordinated are still beyond the pressures available by static means.

In 1963 McQueen et al. [1963] pointed out that Wackerle's [1962] highpressure shock data for quartz and fused quartz were consistent with the density of stishovite. This result indicated that a change in the coordination of silicon could occur in the sub-microsecond time scale of a shock experiment. The recent shock-wave results of McQueen and Marsh [1966], McQueen et al. [1967b], Trunin et al. [1965], Al'tschuler et al. [1965], Ahrens et al. [1969b], and Jones et al. [1968] have shown that the silicates, the spinels, and some of the oxides undergo marked decreases in volume at pressures greater than 300 to $1000 \mathrm{~kb}$. These volume decreases appear to be associated with one or more phase transitions. Shock-wave data have been obtained by McQueen and Marsh [1966], McQueen et al. [1967b], and Trunin et al. [1965] for materials that, on the basis of their chemical composition, are likely to be important in discussions of the composition of the earth's mantle. For some of these materials sufficient shock data are available so that, in addition to the density, the bulk modulus and seismic parameter, $\Phi=(\partial P / \partial \rho)_{s}$, versus pressure of the high-pressure shockinduced phase may be obtained upon suitable reduction of the Hugoniot data. The reduced data yield the pressure, density, and $\partial P / \partial \rho$ along the Hugoniot, the $25^{\circ} \mathrm{C}$ isotherm, the adiabat centered at room temperature, and the metastable Hugoniot (Figure 1). In the case of the adiabat and the Hugoniot, temperatures are also required in order to describe a complete $P-V-T$ (pressure-volume-tem- 


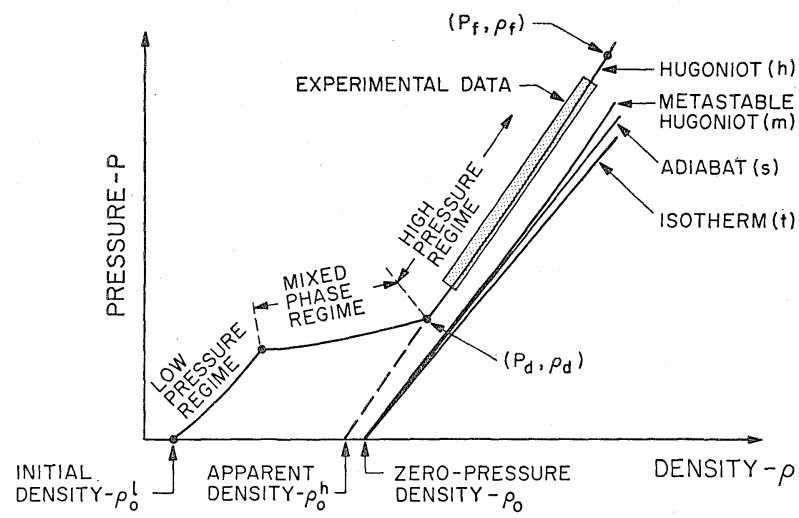

Fig. 1. Pressure-density relations for material undergoing a shock-induced phase change. Low-pressure regime represents Hugoniot of material with zero-pressure density $\rho_{0}{ }^{2}$. High-pressure regime represents Hugoniot of material that has been completely converted to high-pressure phase with zero-pressure density $\rho_{0}$. Metastable Hugoniot, adiabat, and isotherm for high-pressure phase are centered at state $P=0, T=25^{\circ} \mathrm{C}$.

perature) equation of state for the high-pressure material. In these forms the reduced shock data can be applied to the study of the earth's interior.

The zero-pressure densities for the high-pressure phases obtained in the reduction can be compared with the densities of high-pressure polymorph or reaction products produced in static high-pressure quenching experiments on the same or analogous compounds and with the densities of possible polymorphs determined from crystal chemical considerations. Such comparisons may be used to infer the crystal structures of the minerals likely to be present at the high shock pressures and to form a basis for discussions of the crystal structures of minerals present in the deep mantle. The equation of state parameters, zeropressure densities, and probable crystallography of the high-pressure polymorphs and/or reaction products produced in twenty-four rocks and minerals are obtained in the present study.

In the initial analysis of their data McQueen et al. [1967b] employed the high-pressure Hugoniot data independently to derive the density of the highpressure (metastable) phase at standard temperature and pressure. The transformation energies were obtained by assuming that the pressure of the onset of the transition along the Hugoniot represented a state along the phase boundary between the low- and the high-pressure phase, i.e., thermodynamic equilibrium. Wang [1967] questioned this assumption and reported an analysis of these data that employed the linear relation between sound speed and density suggested by Birch [1961] to constrain the zero-pressure density at the foot of the adiabat of the high-pressure phase (hpp) material. Integration along the Hugoniot as an approximation to the virtual thermodynamic paths through the mixed phase region was used to account for the transformation energy. Anderson and 
Kanamori [1968] reduced these and other data to a series of metastable Hugoniot curves, the feet of which were constrained to satisfy the seismic equation of state of Anderson [1967] and thus to yield the zero-pressure density.

In the present analysis we employ the adiabatic zero-pressure bulk modulus (or seismic parameter) and the mean atomic weight to constrain by means of the seismic equation of state [Anderson, 1967], the zero-pressure density of the (metastable) high-pressure phase. Where possible, supplementary thermodynamic data derived from high-pressure quenching experiments are used to calculate appropriate transformation energies.

\section{CALCULATIONAL PROCEDURE}

The raw Hugoniot data for minerals, illustrated in Figures 1 and 3-9, may often be represented as lying in one or more of the three regimes designated as the low-pressure phase, mixed-phase, and high-pressure phase regime. For many of the subject materials the low-pressure regime corresponds to stress-volumeenergy states in material that has yielded under one-dimensional compression and has thus been shocked into states that are in an effectively hydrostatic state of stress; i.e., the principal stresses are nearly equal. In some cases, however (for example, $\mathrm{Al}_{2} \mathrm{O}_{3}$ and $\mathrm{MgO}$ ), significant stress differences appear to be present at Hugoniot states up to substantial stress levels. These instances are discussed below. The mixed-phase region is assumed to represent a mixture of both the high- and the low-pressure phase material, and states in the high-pressure regime are assumed to represent material that has been wholly converted to the high-pressure phase. In the present analysis, we analyze only the shock data in the high-pressure region, although in practice it is often difficult to ascertain the lower pressure limit of this regime. It should be noted that the states lying in the high-pressure regime are achieved by direct shock transition from the low-pressure initial phase which is at standard conditions. No assumption of the equation of state of the low-pressure phase material need be made in the present procedure.

The Hugoniot and other forms of the equation of state are usually formulated in terms of expressions containing one or two adjustable parameters. These equations relate pressure to volume or density along a particular thermodynamic path such as the adiabat or isotherm. The two-parameter equations commonly employed include (A) the equation obtained from the linear shock-particle velocity equation [Rice et al., 1958], (B) the Murnaghan equation, and (C) the Birch-Murnaghan second-order equation.

$$
P=C_{0}^{2}\left(V_{0}-V\right) /\left[V_{0}-S\left(V_{0}-V\right)\right]^{2}
$$

where $C_{0}$ represents the bulk sound speed at zero pressure, and $S$ is the adjustable parameter in the relation of shock velocity to shock particle velocity $\left(U_{s}-U_{p}\right)$ :

$$
U_{s}=C_{0}+S U_{p}
$$

Equation 1 is particularly well suited for fitting raw Hugoniot data. However, the thermodynamic restraints imposed by the linear $U_{s}$ versus $U_{p}$ relation, which has recently been discussed by $\mathbb{R} u$ off [1967], reduced the usefulness of this rela- 
tion for forms of the equation of state other than the Hugoniot. The Murnaghan [1944] equation is

$$
P=\left(K_{0} / n\right)\left[x^{3 n}-1\right]
$$

and the Birch-Murnaghan second-order equation [Birch, 1952] is

$$
P=A\left(x^{7}-x^{5}\right)-B\left(x^{7}-x^{5}\right)\left(x^{2}-1\right)
$$

where $K_{0}$ and $n$, and $A$ and $B$, are the adjustable parameters in equations 2 and 3 , respectively, and where

$$
x=\left(\rho / \rho_{0}\right)^{1 / 3}=\left(V_{0} / V\right)^{1 / 3}
$$

Here, $\rho_{0}$ and $\rho$ are the initial and final density and $V_{0}$ and $V$ are the initial and final specific volume. The significance of the parameters in equations 2 and 3 is discussed by Anderson [1967] and Anderson and Kanamori [1968]. Equation 3 is often written in the form

$$
P=\frac{3}{2} K_{0}\left(x^{7}-x^{5}\right)\left[1-\xi\left(x^{2}-1\right)\right]
$$

where

$$
\begin{gathered}
K_{0}=2 A / 3 \quad \xi=B / A \\
K_{0}{ }^{\prime}=(d K / d P)_{0}=4-\frac{4}{3}(B / A)
\end{gathered}
$$

The zero-pressure bulk modulus $K_{0}$ is related to the bulk sound speed $C_{0}$ and seismic parameter $\Phi$ by

$$
K_{0} / \rho_{0}=C_{0}^{2}=\Phi
$$

As indicated, $K_{0}{ }^{\prime}$ is the pressure derivative of the zero-pressure bulk modulus. Three-parameter equations of state have been proposed for describing shockwave data [Pastine and Piacesi, 1966] and for self consistently describing solids at high temperature and high pressures [Thomsen, 1969].

In practice, it is simpler to use the Birch-Murnaghan equation to fit a series of $P-V$ data or a series of calculated $P-V$ points than to use the Murnaghan equation, because in equation 3 the exponents of $x$ are fixed and hence evaluation of the parameters $A$ and $B$ involves only the solution of a series of linear simultaneous equations. In addition, we note that the Murnaghan equation gives a constant value of $d K / d P=n$, which somewhat limits its flexibility. If the $0^{\circ} \mathrm{K}$ isotherm is cast in the Birch-Murnaghan (equation 3 ) form, the DugdaleMcDonald and the Slater formulas for the elastic Grüneisen ratio at zero pressure are

$$
\gamma_{\mathrm{DM}}=-\frac{1}{2}\left[1+\left(\partial \ln K_{t} / \partial \ln V\right)_{t}\right]
$$

and

$$
\gamma_{\mathrm{S}}=-\frac{1}{6}-\frac{1}{2}\left(\partial \ln K_{t} / \partial \ln V\right)_{t}
$$

These equations càn be conveniently expressed as

$$
\gamma_{\mathrm{DM}}=\frac{3}{2}-\frac{2}{3}(B / A)
$$


and

$$
\gamma_{\mathrm{s}}=\frac{11}{6}-\frac{2}{3}(B / A)
$$

We use equation 3 to fit raw Hugoniot data, and the calculated adiabat, isotherm, and metastable Hugoniot. The subscripts $h, s, t$, and $m$ are used to indicate quantities along the Hugoniot, adiabat, isotherm, and metastable Hugoniot, respectively.

To calculate a fit to the raw Hugoniot data by means of the second-order Birch-Murnaghan equation, it is necessary to obtain an apparent density, $\rho_{0}{ }^{h}$, from the Hugoniot data for the high-pressure phase data. The apparent density is obtained by testing various densities and obtaining the density at zero pressure that satisfies the relation between $\rho$, mean atomic weight $\bar{M}$, and $\phi$

$$
\rho / \bar{M}=a \Phi^{n}
$$

where $a=0.048$ or 0.0475 and $n=0.323$ or $1 / 3$ as given by Anderson [1967] and also employed by Anderson and Kanamori [1968]. Here $\Phi$ is in (kilometers per second) ${ }^{2}$ and $\rho$ is in grams per cubic centimeter. Equation 10, although derived from adiabatic data, is used only for calculational convenience in estimating the zero-pressure density of the hpp from the raw Hugoniot data.

By using an average value of the initial specific volume of the starting low-pressure phase material $V_{0}^{l}$, the increase in internal energy above that at standard temperature and pressure at any point along the Hugoniot $P_{h}, V_{h}$ is given by the Rankine-Hugoniot conservation condition,

$$
\Delta \vec{E}=P_{h}\left(V_{0}^{l}-\overline{-} V_{h}\right) / 2
$$

This increase in internal energy must be equivalent to that obtained upon transformation of the low-pressure phase to the metastable high-pressure phase at standard pressure and temperature, $E_{\text {tr }}$, plus the energy increase along the adiabat of the high-pressure phase (centered at standard temperature and pressure) from $V=V_{0}$ to $V=V_{h}$,

$$
-\int_{V_{\mathbf{0}}}^{V_{h}}(P d V)_{s}
$$

plus, the energy required to increase the pressure at constant volume from the adiabat to the Hugoniot,

$$
\int_{P_{s}}^{P_{l b}}(V / \gamma) d P
$$

Here $V_{0}$ is the specific volume of the high-pressure phase at standard temperature and pressure and $\gamma=V(\partial P / \partial E)_{V}$ is the Grüneisen ratio. For calculational simplicity we have taken $\gamma / V=$ constant. The sensitivity of our results to the particular value employed for Grüneisen's ratio is discussed in the next section. The increase in internal energy is then given by

$$
\Delta E=E_{\mathrm{tr}}-\int_{V_{\mathrm{o}}}^{V_{h}}(P d V)_{s}+\int_{P_{s}}^{P_{h}}[(V / \gamma) d P]_{V}
$$


To obtain $V_{0}\left(\right.$ or $\rho_{0}$ ) and to evaluate numerically the pressure $P_{s}$ on the adiabat at volume $V$ over the range of compressions encompassed by the highpressure regime, the $\Delta E$ term is eliminated between equations 11 and 12 . The following procedure is then employed.

The range of integration in the second term on the right-hand side of equation 12 is subdivided into

$$
-\int_{0}^{P_{s}}(P d V)_{s}=-\int_{0}^{P_{d}}(P d V)_{s}-\int_{P_{d}}^{P_{s}}(P d V)_{s}
$$

where $P_{d}$ corresponds to the adiabatic pressure at the volume $V_{d}$. Here $V_{d}$ is the largest specific volume (or $\rho_{d}$ is the lowest density) in the high-pressure regime (Figure 1). Equation 12 is integrated for a series of trial values of $\rho_{0}$. For each value of $\rho_{0}$ an initial adiabat must be assumed to evaluate the $-\int_{0}^{{ }^{P_{d}}}(P d V)_{s}$ term in equation 13. By using this first estimate of $-\int_{0}^{P_{d}}(P d V)_{s}$, values for $P$ are obtained at a series of volumes from $V_{d}$ to $V_{f}$, where $V_{f}$ is now the least volume (or $\rho_{f}$ is the greatest density) along the Hugoniot in the high-pressure regime (Figure 1). The values obtained for $P_{s}$ versus $V$ are then fitted to the BirchMurnaghan equation. The parameters of this equation are then employed to re-evaluate the first term in equation 13. A new set of values for $P_{s}$ versus $V$ are then obtained by again integrating equation 12 . Such a series of integrations are performed to convergence for each of a series of values of trial density $\rho_{0}$.

The family of Birch-Murnaghan parameters, each corresponding to a trial value of $\rho_{0}$, are tested for deviation from the relation

$$
\rho_{0}^{-}={ }^{-}(2 \bar{M} a A / 3)^{(n / 1+n)}
$$

which is obtained on substitution of equation 3 into equation 10. An interpolated value of the zero-pressure density is then determined, which exactly satisfies equation 10. Equation 12 is then solved iteratively for the final values of $P_{s}$ versus $V$ from $V_{d}$ to $V_{f}$. The adiabat of the high-pressure phase is thus obtained and is fitted to a Birch-Murnaghan equation.

Temperature along the adiabat at a series of volumes from $V$ to $V_{f}$ is then obtained [Walsh and Christian, 1955] from

$$
T_{s}=T_{0} \exp \left\{-\int_{V_{0}}^{V} \gamma d V / V\right\}
$$

where $T_{0}$ is the initial $\left(298^{\circ} \mathrm{K}\right)$ temperature. Similarly, the temperature along the Hugoniot at a series of volumes is obtained from

$$
\int_{T_{s}}^{T_{h}}\left(C_{V} d T_{V}\right)=\left(P_{h}-P_{s}\right) V / \gamma
$$

where $C_{V}$, the specific heat at constant volume, depends on volume and temperature, as given by the Debye model of a solid. The zero-pressure Debye temperature $\theta_{0}$ of the high-pressure phase was obtained from the empirical relation

$$
\theta_{0}=164 \cdot \rho_{0}{ }^{4 / 3}
$$

proposed by Anderson [1965a] for oxides. The accuracy of the temperature 
calculations are sensitive to possible deviations from (17) or non-Debye-like behavior of the Debye temperature and specific heat when the calculated shock temperatures are comparable to or less than the Debye temperature. For materials of interest here, $\theta_{0}$ varies from approximately $500^{\circ}$ to $1000^{\circ} \mathrm{K}$. At higher temperature $C_{V}$ assumes the Dulong-Petit value of $6 \mathrm{cal} / \mathrm{mole}$-atom ${ }^{\circ} \mathrm{K}$.

The position of the isotherm relative to that of the adiabat is again calculated at a series of volumes from $V_{d}$ to $V_{f}$ from the expression

$$
P_{t}=P_{s}-\int_{T_{0}}^{T_{a}}\left(\frac{\gamma}{V} C_{V} d T\right)_{V}
$$

Finally, the pressure along the metastable Hugoniot at a series of volumes is given by

$$
P_{m}=\left(\Delta E-E_{\mathrm{tr}}\right) / R
$$

where

$$
R=\left(V_{0}-V\right) / 2-(V / \gamma)
$$

\section{RESULTS OF CALCULATIONS}

By using the methods outlined above, the shock-wave data summarized in Table 1 were reduced so as to obtain the zero-pressure densities and the pressure along the adiabats, the $25^{\circ} \mathrm{C}$ isotherms, and the metastable Hugoniot at a series of volumes. To apply these results to the earth, we have calculated values of $\Phi$ and the corresponding temperature along the adiabat and Hugoniot (Table 2). Typical results for $\Phi$ and $P_{s}, P_{t}$, and $P_{h}$ for periclase, alumina, stishovite, and the high-pressure phase of Stillwater bronzitite, Hortonolite dunite, and Twin Sisters dunite are given in Table 2 . Our best set of calculated parameters for the high-pressure phases that undergo phase transitions to unknown structures are listed in Table 3. For most of these minerals the zero-pressure densities obtained are 2 to $9 \%$ higher than the values recently obtained by Wang [1967] and Anderson and Kanamori [1968]. Anderson and Kanamori used a slightly different zero-pressure constraint and their estimates of $\rho_{0}$ refer to high temperatures. In general, it is difficult to infer the lowest pressure at which the highpressure part of the Hugoniot represents only the pressure-volume behavior of the high-pressure phase. This is usually done by examining the shock-velocityparticle relation or the pressure-volume relation. We have examined the effect of varying $P_{d}$ (that is, the lower pressure limit of the high-pressure phase data points) on the determination of the zero-pressure density and equation of state parameters of the high-pressure phase. Where sufficient data points exist, the calculated zero-pressure density increases and approaches the value, which is presumably characteristic of a hpp, as points that are possibly in the mixedphase region are excluded from the analysis (Table 4).

The use of only the higher-pressure data points tends to give higher densities in the present analysis than the results of Wang [1967]. The differing constraints on the zero-pressure density of the hpp of Wang's analysis, in which the Birch relation was used to infer the zero-pressure density, and that of Anderson and 
TABLE 1. Parameters Used to Reduce Shock-Wave Data

\begin{tabular}{|c|c|c|c|c|c|c|}
\hline Starting Material & $\begin{array}{l}\text { Initial } \\
\text { Density, } \\
\mathrm{g} / \mathrm{cm}^{3}\end{array}$ & $\begin{array}{c}\text { Mean } \\
\text { Atomic } \\
\text { Weight, } \\
\text { g/mole-atom }\end{array}$ & $\begin{array}{l}\text { Number } \\
\text { of Data } \\
\text { Points }\end{array}$ & $\begin{array}{c}\text { Lowest } \\
\text { Pressure, } \\
\text { kb }\end{array}$ & $\begin{array}{c}\text { Highest } \\
\text { Pressure, } \\
\text { kb }\end{array}$ & $\begin{array}{c}\text { Transition } \\
\text { Energy, } \\
10^{10} \mathrm{ergs} / \mathrm{g}\end{array}$ \\
\hline \multicolumn{7}{|l|}{$\mathrm{Al}_{2} \mathrm{O}_{3}$ corundum } \\
\hline $\mathrm{Al}_{2} \mathrm{O}_{3}$ ceramic $^{a, b}$ & 3.829 & 20.39 & 10 & 635 & 1131 & 0.0 \\
\hline $\mathrm{MgO}$ periclase $^{a}$ & 3.58 & 20.16 & 19 & 202 & 1258 & 0.0 \\
\hline $\mathrm{MgO}$ periclase $^{c}$ & 3.425 & 20.16 & 3 & 345 & 2581 & 0.0 \\
\hline $\mathrm{SiO}_{2} \propto$ quartz qua $^{c, d}$ & 2.654 & 20.03 & 15 & 414 & 1974 & 0.804 \\
\hline $\mathrm{MnO}_{2}$ pyrolusite $^{a}$ & 4.31 & 28.98 & 17 & 183 & 1202 & 0.0 \\
\hline $\mathrm{MgAl}_{2} \mathrm{O}_{4}$ spinel $^{a}$ & 3.42 & 20.32 & 9 & 740 & 1158 & 0.03 \\
\hline $\mathrm{Al}_{2} \mathrm{SiO}_{5}$ sillimanite ${ }^{a}$ & 2.71 & 20.3 & 11 & 584 & 1099 & 0.44 \\
\hline $\mathrm{Al}_{2} \mathrm{SiO}_{5}$ andalusite ${ }^{a}$ & 3.08 & 20.3 & 12 & 594 & 1158 & 0.44 \\
\hline $\mathrm{Fe}_{3} \mathrm{O}_{4}$ magnetite ${ }^{a}$ & 5.120 & 33.08 & 10 & 853 & 1310 & 0.13 \\
\hline $\mathrm{Fe}_{2} \mathrm{O}_{3}$ hematite $^{a}$ & 5.00 & 31.9 & 10 & 896 & 1421 & 0.71 \\
\hline $\mathrm{Mg}_{2} \mathrm{SiO}_{4}$ forsterite ${ }^{a}$ & 3.05 & 20.1 & 6 & 664 & 1035 & 0.67 \\
\hline $\mathrm{MgSiO}_{3}$ enstatite $^{a}$ & 2.71 & 20.1 & 4 & 300 & 637 & 0.85 \\
\hline Bronzitite (Mont.) ${ }^{a}$ & 3.28 & 21.2 & 13 & 655 & 1090 & 0.85 \\
\hline \multicolumn{7}{|l|}{ Twin Sisters dunite } \\
\hline (Wash. $)^{a}$ & 3.32 & 20.9 & 13 & 831 & 1123 & 0.67 \\
\hline Olivinite $\mathrm{I}^{e}$ & 3.31 & 21.2 & 4 & 755 & 5050 & 0.67 \\
\hline $\begin{array}{l}\text { Hortonolite dunite } \\
\quad(\text { S. Africa })^{a}\end{array}$ & 3.79 & 25.1 & 15 & 687 & 1190 & 0.3 \\
\hline Fayalite (Rockport) ${ }^{a}$ & 4.25 & 29.1 & 5 & 696 & 1137 & 0.3 \\
\hline \multicolumn{7}{|l|}{ Eclogite } \\
\hline$(\text { Healdsburg) })^{a}$ & 3.41 & 22.3 & 6 & 817 & 1078 & 0.85 \\
\hline Anorthosite (N. Y.) ${ }^{a}$ & 2.73 & 21.0 & 14 & 331 & 952 & 0.86 \\
\hline \multicolumn{7}{|l|}{ Oligoclase } \\
\hline$($ Muskwa Lake)f & 2.63 & 20.49 & 7 & 464 & 674 & 0.97 \\
\hline Albitite $(\text { Pa. })^{a}$ & 2.61 & 20.4 & 7 & 410 & 904 & 0.99 \\
\hline \multicolumn{7}{|l|}{ Microcline } \\
\hline$(\text { Ontario })^{f}$ & 2.561 & 21.4 & 5 & 296 & 576 & 1.28 \\
\hline 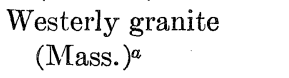 & 2.63 & 20.6 & 8 & 408 & 919 & 0.8 \\
\hline
\end{tabular}

${ }^{a}$ McQueen and Marsh [1966]; McQueen et al. [1967b].

${ }^{b}$ Ahrens et al. [1968].

c Al'tshuler et al. [1965].

${ }^{d}$ Wackerle [1962].

e Trunin et al. [1965].

${ }^{f}$ Ahrens et al. [1969b].

Kanamori [1968], in which the slope of the metastable Hugoniot determined the density from the seismic equation of state (with parameters $a=0.0475$ and $n=1 / 3$ ), tended to give consistently lower densities than the present analysis.

In the case of quartz the number of high-pressure data points can be increased by adding the values obtained by Al'tschuler et al. [1965] to those of Wackerle [1962]. This computation also increases the calculated high-pressure density, giving good agreement with the accepted value of $4.29 \mathrm{~g} / \mathrm{cm}^{3}$ for stishovite (Table 4).

The calculated zero-pressure density and the parameters of the adiabatic equations of state depend on the values of the parameters in the seismic equa- 
TABLE 2. Calculated Equations of State, High-Pressure Phase

\begin{tabular}{cccccccc}
\hline \hline$\rho$, & $P_{h}$, & $\Phi_{h}$, & & $\rho$, & $P_{s,}$ & $\Phi_{s,}$ \\
$\mathrm{~g} / \mathrm{cm}^{3}$ & $\mathrm{~kb}$ & $(\mathrm{~km} / \mathrm{sec})^{2}$ & $K_{h}{ }^{\prime}$ & $\mathrm{g} / \mathrm{cm}^{3}$ & $\mathrm{~kb}$ & $(\mathrm{~km} / \mathrm{sec})^{2}$ & $K_{s}{ }^{\prime}$ \\
\hline
\end{tabular}

(a) Seismic Parameters $K_{h}{ }^{\prime}$ and $K_{s}{ }^{\prime}$

$\mathrm{MgO}$, crystal

$\begin{array}{rrrrrrrr}3.584 & 0 . & 45.5 & 4.54 & 3.584 & 0 . & 46.7 & 4.03 \\ 3.984 & 219 & 64.6 & 4.12 & 3.984 & 219 & 63.1 & 3.68 \\ 4.384 & 520 & 86.0 & 3.87 & 4.384 & 506 & 80.7 & 3.46 \\ 4.784 & 912 & 109.6 & 3.70 & 4.784 & 867 & 99.4 & 3.31 \\ 5.024 & 1195 & 124.8 & 3.62 & 5.024 & 1119 & 111.1 & 3.24\end{array}$

$\mathrm{Al}_{2} \mathrm{O}_{3}$, ceramic

$\begin{array}{rrrrrrrr}4.27 & 204 & 80.8 & 4.11 & 3.99 & 0 . & 64.3 & 3.91 \\ 4.51 & 415 & 95.4 & 3.94 & 4.35 & 271 & 82.1 & 3.63 \\ 4.75 & 663 & 110.7 & 3.81 & 4.72 & 599 & 100.4 & 3.43 \\ 4.99 & 948 & 126.8 & 3.70 & 5.00 & 900 & 115.1 & 3.32 \\ 5.24 & 1288 & 144.4 & 3.61 & 5.24 & 1192 & 128.1 & 3.24\end{array}$

$\mathrm{SiO}_{2}$, Stishovite

$\begin{array}{rrrrrrrr}4.40 & 128 & 118.2 & 4.15 & 4.29 & 0 . & 85.3 & 3.03 \\ 4.70 & 521 & 144.3 & 3.93 & 4.59 & 274 & 97.2 & 2.81 \\ 5.00 & 995 & 172.1 & 3.76 & 4.89 & 582 & 108.3 & 2.62 \\ 5.30 & 1556 & 201.3 & 3.63 & 5.34 & 1101 & 123.5 & 2.37 \\ 5.51 & 2007 & 222.9 & 3.56 & 5.51 & 1320 & 128.9 & 2.28\end{array}$

Twin Sisters dunite

$\begin{array}{rrrrrrrr}4.465 & 312 & 83.0 & 2.62 & 4.12 & 0 & 79.3 & 2.64 \\ 4.825 & 678 & 94.5 & 2.34 & 4.48 & 305 & 89.8 & 2.33 \\ 4.975 & 846 & 99.0 & 1.99 & 4.84 & 643 & 98.4 & 2.04 \\ 5.185 & 1095 & 104.8 & 1.14 & 5.19 & 990 & 104.7 & 1.77\end{array}$

Hortonolite dunite

$\begin{array}{rrrrrrrr}4.92 & 167 & 72.6 & 2.74 & 4.75 & 0 & 67.4 & 2.36 \\ 5.14 & 332 & 78.1 & 2.60 & 5.21 & 341 & 77.9 & 1.97 \\ 5.60 & 715 & 88.6 & 2.34 & 5.67 & 710 & 83.1 & 1.56 \\ 6.06 & 1140 & 97.5 & 2.09 & 6.11 & 1076 & 85.3 & 1.14\end{array}$

Bronzitite

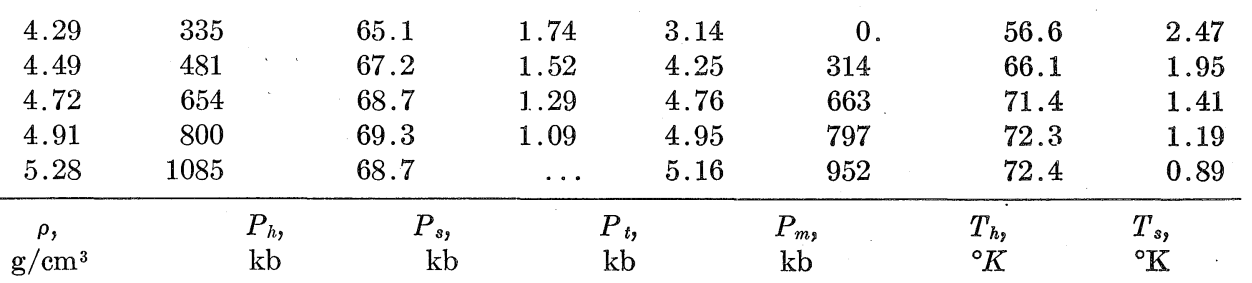

(b) Pressures along Hugoniot, Adiabat, $298^{\circ} \mathrm{K}$ Isotherm, and Metasiable Hugoniot;

Temperatures along Hugoniot and Adiabat

$\mathrm{MgO}$, crystal

$\begin{array}{rrrrrrr}3.95 & 199 & 198 & 195 & 199 & 379 & 343 \\ 4.18 & 357 & 351 & 347 & 356 & 475 & 370 \\ 4.44 & 572 & 555 & 549 & 571 & 683 & 400 \\ 4.75 & 878 & 837 & 827 & 877 & 1136 & 4.33 \\ 5.05 & 1225 & 1144 & 1134 & 1224 & 1744 & 463\end{array}$


Table 2 (Continued)

\begin{tabular}{|c|c|c|c|c|c|c|}
\hline $\begin{array}{c}\rho, \\
\mathrm{g} / \mathrm{cm}^{3}\end{array}$ & $\begin{array}{l}P_{h} \\
\mathrm{~kb}\end{array}$ & $\begin{array}{l}P_{s} \\
\mathrm{~kb}\end{array}$ & $\begin{array}{l}P_{t} \\
\mathrm{~kb}\end{array}$ & $\begin{array}{l}P_{m}, \\
\mathrm{~kb}\end{array}$ & $\begin{array}{l}T_{h}, \\
{ }^{\circ} \mathrm{K}\end{array}$ & $\begin{array}{l}T_{s}, \\
{ }^{\circ} \mathrm{K}\end{array}$ \\
\hline \multicolumn{7}{|c|}{$\mathrm{Al}_{2} \mathrm{O}_{3}$, ceramic } \\
\hline 4.69 & 605 & 575 & 570 & 584 & 849 & 371 \\
\hline 4.87 & 798 & 753 & 747 & 771 & 1092 & 387 \\
\hline 5.05 & 1029 & 962 & 954 & 992 & 1444 & 405 \\
\hline 5.24 & 1293 & 1195 & 1188 & 1245 & 1870 & 422 \\
\hline \multicolumn{7}{|c|}{$\mathrm{SiO}_{2}$, Stishovite } \\
\hline 4.50 & 256 & 211 & 209 & 211 & 1245 & 313 \\
\hline 4.72 & 546 & 406 & 404 & 407 & 3045 & 326 \\
\hline 4.95 & 912 & 647 & 642 & 650 & 5432 & 341 \\
\hline 5.21 & 1376 & 942 & 934 & 952 & 8653 & 355 \\
\hline 5.51 & 1995 & 1323 & 1314 & 1346 & 13130 & 372 \\
\hline \multicolumn{7}{|c|}{ Twin Sisters dunite } \\
\hline 4.76 & 610 & 568 & 564 & 570 & 1479 & 333 \\
\hline 4.84 & 678 & 644 & 641 & 648 & 1748 & 337 \\
\hline 4.93 & 790 & 726 & 722 & 731 & 2047 & 341 \\
\hline 5.01 & 889 & 812 & 810 & 819 & 2329 & 345 \\
\hline 5.10 & 995 & 904 & 901 & 912 & 2687 & 349 \\
\hline 5.19 & 1107 & 1007 & 997 & 1012 & 3079 & 353 \\
\hline \multicolumn{7}{|c|}{ Hortonolite dunite } \\
\hline 5.71 & 816 & 747 & 744 & 751 & 2614 & 335 \\
\hline 5.81 & 905 & 825 & 822 & 830 & 2917 & 338 \\
\hline 5.91 & 1000 & 910 & 908 & 917 & 3249 & 341 \\
\hline 6.02 & 1102 & 1000 & 997 & 1008 & 3605 & 344 \\
\hline 6.13 & 1209 & 1094 & 1090 & 1105 & 4043 & 348 \\
\hline \multicolumn{7}{|c|}{ Bronzitite } \\
\hline 4.50 & 491 & 486 & 485 & 489 & 531 & 338 \\
\hline 4.63 & 589 & 577 & 575 & 582 & 778 & 344 \\
\hline 4.77 & 695 & 674 & 672 & 681 & 1033 & 350 \\
\hline 5.03 & 893 & 856 & 853 & 868 & 1592 & 360 \\
\hline 5.28 & 1088 & 1032 & 1029 & 1050 & 2148 & 370 \\
\hline
\end{tabular}

tion (Table 5). The values $a=0.048$ and $n=0.323$ are preferred and used in Table 3, since these values are based on fitting strictly adiabatic zero-pressure moduli to density and mean atomic weight. Recently Anderson [1969] has proposed that the values $a=0.0492$ and $n=1 / 3$ be used in reducing the highpressure shock data. These parameters will reduce the densities inferred for the high-pressure phases by 0.04 to $0.11 \mathrm{~g} / \mathrm{cm}^{3}$.

We note that both moduli (and the zero-pressure densities) of the $\mathrm{MgO}$ and $\mathrm{Al}_{2} \mathrm{O}_{3}$, when estimated from the shock data with these equations of state, are high as compared with their accepted ultrasonic values of 1622 and $2521 \mathrm{~kb}$ and observed densities of 3.584 and $3.988 \mathrm{~g} / \mathrm{cm}^{3}$. A deviation in this direction can be expected, since the ultrasonic values of $K_{0 s}$ for these materials both lie above the $a=0.048$ and $n=0.323$ equation of state relation, 
TABLE 3. Equation of State Parameters, High-Pressure Phases

\begin{tabular}{|c|c|c|c|c|c|c|c|c|c|c|c|c|c|c|c|}
\hline & & Hugoniot & & & & & abat & & & & otherm & & Metastab & le Hugo & oniot \\
\hline Starting Material ${ }^{a}$ & $\begin{array}{c}\text { Apparent } \\
\text { Density } \\
\rho_{0 h} \\
\mathrm{~g} / \mathrm{cm}^{3}\end{array}$ & $\begin{array}{c}\text { Apparent } \\
\text { Bulk } \\
\text { Modulus } \\
K_{0 h} \\
\text { kb }\end{array}$ & $\xi_{h}$ & $K_{0 h^{\prime}}$ & $\begin{array}{c}\text { Calculated } \\
\text { Density } \\
\rho_{0} \\
\mathrm{~g} / \mathrm{cm}^{3}\end{array}$ & $\begin{array}{c}\text { Grüneisen } \\
\text { Ratio } \\
\text { ro }\end{array}$ & $\begin{array}{c}\text { Bulk } \\
\text { Modulus } \\
K_{0 s} \\
\mathrm{~kb}\end{array}$ & $\xi_{3}$ & $K_{0 s^{\prime}}$ & $\begin{array}{c}\text { Bulk } \\
\text { Modulus } \\
K_{0 t} \text {, } \\
\text { kb }\end{array}$ & $\xi_{t}$ & $K_{0 t^{\prime}}$ & $\begin{array}{c}\text { Bulk } \\
\text { Modulus } \\
K_{\text {om }} \text {, } \\
\text { kb }\end{array}$ & $\xi_{m}$ & $K_{0 m^{\prime}}$ \\
\hline $\mathrm{Al}_{2} \mathrm{O}_{3}$ corundum crystal $^{b}$ & 3.95 & 2968 & 0.578 & 3.23 & $3.94^{b}$ & $1.1^{b}$ & $2931^{b}$ & $0.66^{b}$ & $3.12^{b}$ & $2917^{b}$ & $0.66^{b}$ & $3.13^{b}$ & 2903 & 0.52 & 3.31 \\
\hline $\mathrm{Al}_{2} \mathrm{O}_{3}$ ceramic $^{b}$ & 4.03 & 3233 & 0.403 & 3.46 & $4.04^{b}$ & $1.1^{b}$ & $3255^{b}$ & $0.64^{b}$ & $3.15^{b}$ & $3235^{b}$ & $0.63^{b}$ & $3.16^{b}$ & 3224 & 0.63 & 3.10 \\
\hline MgO periclase ${ }^{b, c}$ & 3.69 & 2318 & 0.417 & 3.44 & $3.70^{b}$ & $1.1^{b}$ & $2336^{b}$ & $0.62^{b}$ & $3.18^{b}$ & $2319^{b}$ & $0.61^{b}$ & $3.19^{b}$ & 2315 & 0.464 & 3.37 \\
\hline MgO periclase ${ }^{b, d}$ & 3.77 & 2526 & 0.191 & 3.75 & 3.82 & 1.1 & 2668 & 0.58 & 3.22 & 2650 & 0.576 & 3.23 & 2624 & 0.396 & 3.47 \\
\hline $\mathrm{SiO}_{2} \alpha$ quartz $^{b}$ & 4.26 & 4272 & 0.498 & 4.66 & $4.32^{b}$ & $0.82^{b}$ & $4205^{b}$ & $0.84^{b}$ & $2.88^{b}$ & $4187^{b}$ & $0.84^{b}$ & $2.87^{b}$ & 4176 & 0.74 & 3.00 \\
\hline $\mathrm{MnO}_{2}$ pyrolusite & 5.20 & 3011 & 1.25 & 2.33 & 5.29 & 0.67 & 3400 & 1.74 & 1.67 & 3390 & 1.75 & 1.67 & 3374 & 1.71 & 1.72 \\
\hline $\mathrm{MgAl}_{2} \mathrm{O}_{4}$ spinel & 4.15 & 3651 & 0.537 & 3.28 & 4.19 & 0.79 & 3819 & 1.06 & 2.59 & 3869 & 1.01 & 2.66 & 3805 & 0.991 & 2.68 \\
\hline $\mathrm{Al}_{2} \mathrm{SiO}_{5}$ sillimanite & 3.93 & 2972 & 0.803 & 2.93 & 4.00 & 0.57 & 3187 & 1.40 & 2.33 & 2781 & 1.57 & 1.90 & 3179 & 1.37 & 2.17 \\
\hline $\mathrm{Al}_{2} \mathrm{SiO}_{5}$ andalusite & 3.90 & 2870 & 0.636 & 3.15 & 3.95 & 0.73 & 3045 & 1.16 & 2.46 & 2910 & 1.25 & 2.33 & 3037 & 1.10 & 2.53 \\
\hline $\mathrm{Fe}_{3} \mathrm{O}_{4}$ magnetite & 6.27 & 4411 & 1.45 & 2.06 & 6.30 & 0.39 & 4488 & 1.66 & 1.79 & 4483 & 1.66 & 1.79 & 4487 & $\mathbb{1} .64$ & 1.81 \\
\hline $\mathrm{Fe}_{2} \mathrm{O}_{3}$ hematite & 5.94 & 3963 & 1.41 & 2.13 & 5.96 & 0.49 & 3991 & 1.52 & 1.98 & 3814 & 1.59 & 1.88 & 3993 & 1.50 & 2.00 \\
\hline $\mathrm{Mg}_{2} \mathrm{SiO}_{4}$ forsterite & 4.24 & 4195 & 1.19 & 2.41 & 4.31 & 1.0 & 4425 & 2.22 & 1.05 & 4307 & 2.20 & 1.07 & 4427 & 2.20 & 1.06 \\
\hline $\mathrm{MgSiO}_{3}$ enstatite & 4.07 & 3491 & 3.11 & 2.86 & 4.20 & 0.15 & 4031 & 4.23 & -1.64 & 3953 & 4.25 & -1.66 & 4027 & 4.31 & -1.75 \\
\hline Bronzitite (Mont.) & 3.79 & 2335 & 1.13 & 2.49 & 3.74 & 0.74 & 2117 & 1.14 & 2.48 & 2109 & 1.14 & 2.48 & 2113 & 1.09 & 2.55 \\
\hline Twin Sisters dunite (Wash.) & 4.11 & 3245 & 0.564 & 3.25 & 4.12 & 0.82 & 2367 & 1.01 & 2.65 & 3253 & 1.01 & 2.65 & 3257 & 0.940 & 2.75 \\
\hline Olivinite I & 4.40 & 4111 & 0.201 & 3.73 & 4.58 & 0.93 & 4840 & 0.861 & 2.85 & 4853 & 0.824 & 2.90 & 4757 & 0.741 & 3.01 \\
\hline Hortonolite dunite (S. Africa) & 4.69 & 3163 & 0.854 & 2.86 & 4.75 & 0.69 & 3319 & 1.22 & 2.37 & 3361 & 1.16 & 2.45 & 3311 & 1.17 & 2.44 \\
\hline Fayalite (Rockport) & 5.17 & 2962 & 1.35 & 2.19 & 5.31 & $1.0^{\circ}$ & 3319 & 1.87 & 1.50 & 3277 & 1.87 & 1.50 & 3325 & 1.86 & 1.52 \\
\hline Eclogite (Healdsburg) & 3.69 & 1701 & 0.656 & 3.13 & 3.61 & 1.00 & 1555 & 0.755 & 2.99 & 1499 & 0.69 & 3.09 & 1542 & 0.627 & 3.16 \\
\hline Anorthosite (N. Y). & 3.68 & 2013 & 0.685 & 3.09 & 3.71 & 0.70 & 2084 & 1.20 & 2.40 & 2086 & 1.20 & 2.40 & 2092 & 1.14 & 2.48 \\
\hline Oligoclase (Muskwa Lake) & 3.65 & 2074 & 0.653 & 3.13 & 3.69 & $1.0^{e}$ & 2198 & 1.60 & 1.87 & 2177 & 1.62 & 1.85 & 2193 & 1.55 & 1.93 \\
\hline Albitite $\left(\mathrm{Pa}_{\mathrm{o}}\right)$ & 3.78 & 2516 & 0.606 & 3.16 & 3.18 & $1.0^{\circ}$ & 2550 & 1.63 & 1.82 & 2524 & 1.65 & 1.80 & 2542 & 1.58 & 1.89 \\
\hline Microcline (Ontario) & 3.52 & 1587 & 0.855 & 2.86 & 3.50 & $1.0^{e}$ & 1563 & 1.47 & 2.04 & 1353 & 1.49 & 2.01 & 1561 & 1.42 & 2.11 \\
\hline Westerly granite (Mass.) & 3.91 & 2727 & 0.566 & 3.25 & 3.96 & 0.62 & 2907 & 1.32 & 2.24 & 2514 & 1.58 & 1.90 & 2889 & 1.31 & 2.26 \\
\hline
\end{tabular}

a Data sources given in Table 1.

b Preferred value given in Table 6

- McQueen and Marsh [1966].

\& Al'tschuler et al. [1966].

- Grüneisen ratio set to value 1.0. 
TABLE 4. Effect of Varying Range of Data

\begin{tabular}{lccccccc}
\hline \multicolumn{1}{c}{ Starting Material } & $\begin{array}{c}\text { Number of } \\
\text { Data Points }\end{array}$ & $\begin{array}{c}\text { Lowest } \\
\text { Pressure, } \\
\mathrm{kb}\end{array}$ & $\begin{array}{c}\text { Highest } \\
\text { Pressure, } \\
\mathrm{kb}\end{array}$ & $\begin{array}{c}\text { Density, } \\
\mathrm{g} / \mathrm{cm}^{3}\end{array}$ & $\begin{array}{c}K_{0 s}, \\
\mathrm{~kb}\end{array}$ & $\xi_{s}$ & $K_{0 s^{\prime}}$ \\
\hline Bronzitite (Mont.) $^{a}$ & 21 & 531 & 1090 & 3.76 & 2305 & 1.32 & 2.23 \\
Bronzitite (Mont.) $^{a}$ & 17 & 601 & 1090 & 3.81 & 2447 & 1.35 & 2.20 \\
Bronzitite (Mont.) $^{a}$ & 15 & 643 & 1090 & 3.82 & 2456 & 1.33 & 2.23 \\
Bronzitite (Mont.) $^{a}$ & 13 & 655 & 1090 & 3.82 & 2474 & 1.35 & 2.18 \\
Twin Sisters dunite $^{a}$ & 15 & 734 & 1123 & 4.08 & 3085 & 0.993 & 2.68 \\
Twin Sisters dunite $^{a}$ & 13 & 831 & 1123 & 4.11 & 3149 & 0.950 & 2.73 \\
Quartz $^{b}$ & 12 & 414 & 725 & 4.18 & 3916 & 3.295 & -0.394 \\
Quartz $^{c}$ & 15 & 414 & 1974 & 4.31 & $4205 \alpha$ & 0.837 & 2.88 \\
\hline
\end{tabular}

a McQueen and Marsh [1966]; McQueen et al. [1967b].

${ }^{\circ}$ Wackerle [1962].

c Wackerle [1962]; Al'tshuler et al. [1966].

The deviations of the inferred zero-pressure densities of $\mathrm{MgO}$ and $\mathrm{Al}_{2} \mathrm{O}_{3}$ from the starting densities are considered sufficiently small (see next section), so that for purposes of further calculation we have assumed that the normal zeropressure densities are the appropriate values. Upon so constraining the zeropressure densities (Table 6), we note that the resulting adiabatic bulk moduli for single-crystal and ceramic $\mathrm{Al}_{2} \mathrm{O}_{3}$ of 3268 and $2842 \mathrm{~kb}$ and of $\mathrm{MgO}$ of $1746 \mathrm{~kb}$ are too high as compared with the ultrasonic values of 2521 and $1622 \mathrm{~kb}$, recently reported by Anderson et al. [1968]. In the case of $\mathrm{Al}_{2} \mathrm{O}_{3}$ this result is not unexpected, since, at low pressures (below $300 \mathrm{~kb}$ ), Hugoniot data are known to be offset in pressure by $\sim 40$ to $50 \mathrm{~kb}$ above the isothermal X-ray data of PerezAlbuerne and Drickamer [1965]. This offset above the isothermal data in the shock pressure is believed to be the result of residual stress differences in the high-pressure shock state [Ahrens et al., 1968]. This so-called strength effect

TABLE 5. Effect of Varying Equation of State $\left(\rho_{0} / \bar{M}=a \Phi^{n}\right)$

\begin{tabular}{lcccccc}
\hline \multicolumn{1}{c}{ Starting Material } & $\begin{array}{c}a, \\
\text { mole-atom } / \mathrm{cm}^{3}\end{array}$ & $n$ & $\begin{array}{c}\rho_{0}, \\
\mathrm{~g} / \mathrm{cm}^{3}\end{array}$ & $\begin{array}{c}K_{0 s}, \\
\mathrm{~kb}\end{array}$ & $\xi_{s}$ & $K_{0 s^{\prime}}$ \\
\hline $\mathrm{MgO}^{*}$ & 0.048 & 0.323 & 3.70 & 2336 & 0.62 & 3.18 \\
$\mathrm{MgO}^{*}$ & 0.0475 & $1 / 3$ & 3.63 & 1981 & 0.37 & 3.59 \\
$\mathrm{MgO}^{*}$ & 0.0519 & 0.323 & 3.53 & 1524 & -0.168 & 4.22 \\
$\mathrm{MgO}^{*}$ & $\dagger$ & $\dagger$ & 3.584 & 1746 & 0.077 & 3.90 \\
$\mathrm{MgO}$ & 0.048 & 0.323 & 3.82 & 2668 & 0.58 & 3.22 \\
MgO & 0.0475 & $1 / 3$ & 3.73 & 2193 & 0.35 & 3.53 \\
Bronzitite* & 0.048 & 0.323 & 3.82 & 2474 & 1.352 & 2.18 \\
Bronzitite* & 0.0475 & $1 / 3$ & 3.70 & 1995 & 1.083 & 2.56 \\
Twin Sisters dunite* & 0.048 & 0.323 & 4.11 & 3149 & 0.950 & 2.73 \\
Twin Sisters dunite* & 0.0475 & $1 / 3$ & 4.08 & 3085 & 0.993 & 2.68 \\
\hline
\end{tabular}

* McQueen and Marsh [1966]; McQueen et al. [1967b].

Initial density fixed, uncorrected for strength effects.

\$ Al'shuler et al. [1966]. 
TABLE 6. Equations of State, Known Zero-Pressure Density, Strength Effects

\begin{tabular}{|c|c|c|c|c|c|c|c|}
\hline \multirow{2}{*}{ Material } & \multicolumn{3}{|c|}{$K_{0 s}$} & \multicolumn{3}{|c|}{$K_{0 t}$} & \multirow[b]{2}{*}{$K_{0} i^{\prime}$} \\
\hline & $\gamma_{0}$ & & $\xi_{s}$ & $K_{0 s^{\prime}}$ & & $\xi_{\imath}$ & \\
\hline \multicolumn{8}{|l|}{$\mathrm{MgO} ; \rho_{0}=3.584 \mathrm{~g} / \mathrm{cm}^{3}$} \\
\hline Shock (strength corrected ${ }^{a}$ ) & 1.52 & 1675 & -0.020 & 4.03 & 1648 & -0.049 & 4.06 \\
\hline Shock (raw) & 1.46 & 1746 & 0.077 & 3.90 & 1720 & 0.054 & 3.93 \\
\hline Ultrasonic $^{b}$ & 1.54 & 1622 & -0.338 & $4.45^{c}$ & 1599 & -0.390 & 4.52 \\
\hline \multicolumn{8}{|l|}{$\mathrm{Al}_{2} \mathrm{O}_{3} ; \rho_{0}=3.988 \mathrm{~g} / \mathrm{cm}^{3}$} \\
\hline \multicolumn{8}{|l|}{ Shock crystal } \\
\hline (strength corrected ${ }^{d}$ ) & 1.12 & 2919 & 0.58 & 3.23 & 2901 & 0.57 & 3.24 \\
\hline Shock ceramic & & & & & & & \\
\hline (strength corrected ${ }^{d}$ ) & 1.46 & 2563 & 0.06 & 3.91 & 2532 & 0.042 & 3.94 \\
\hline Shock crystal (raw) & 0.92 & 3268 & 0.86 & 2.85 & 3255 & 0.86 & 2.86 \\
\hline Shock ceramic (raw) & 1.26 & 2842 & 0.35 & 3.53 & 2818 & 0.34 & 3.55 \\
\hline Ultrasonic $^{b}$ & 1.32 & 2521 & 0.030 & $3.96^{c}$ & 2505 & 0.0075 & 3.99 \\
\hline $\mathrm{SiO}_{2} ; \rho_{0}=4.287 \mathrm{~g} / \mathrm{cm}^{3}$ & 0.995 & 3659 & 0.727 & 3.03 & 3627 & 0.722 & 3.04 \\
\hline $\mathrm{MnO}_{2} ; \rho_{0}=5.233 \mathrm{~g} / \mathrm{cm}^{3}$ & 0.55 & 3027 & 1.43 & 2.09 & 3019 & 1.43 & 2.09 \\
\hline
\end{tabular}

${ }^{a}$ Ahrens and Linde [1967].

${ }^{\circ}$ Anderson et al. [1968].

- Values obtained from measured values of $\left(d K_{0 s} / d P\right)_{T}$ using formula given by Chung [1967].

${ }^{d}$ Ahrens et al. [1968].

occurs if the material is shocked to a state along the deformational Hugoniot and is able to support a shear stress of magnitude, $\tau_{m}$. The Hugoniot will be offset above the (isothermal) hydrostat (shock heating being neglected) by a stress [Rice et al., 1958]

$$
\Delta P_{h}=\frac{4}{3} \tau_{m}
$$

The relation of the offset of the Hugoniot curve to the Hugoniot elastic limit (HEL) and the isothermal and adiabatic hydrostat is indicated in Figure 2. In general, this shear stress, $\tau_{m}$ is related to the stress parallel and perpendicular to the shock propagation direction, $P_{h}$ and $P_{p}$, by

$$
\tau_{m}=\frac{1}{2}\left(P_{h}-P_{p}\right)
$$

In the hydrostatic case, $P_{h}=P_{p}$ and $\tau_{m}=0$.

Most of the materials under discussion in this paper undergo shock-induced phase changes in which the crystalline lattice undergoes complete rearrangement. In these cases it appears unlikely that an appreciable shock-strength effect will be present in the high-pressure phase material. On the basis of this argument and the fact that the zero-pressure density of stishovite (4.18-4.34 depending on the data range employed in the analysis) inferred from the high-pressure shock data (Table 3 ) is in good agreement with its known zero-pressure value of $4.29 \mathrm{~g} / \mathrm{cm}^{3}$, we infer that a strength effect will be present to a significant extent only in material that does not undergo a shock-induced phase change. 


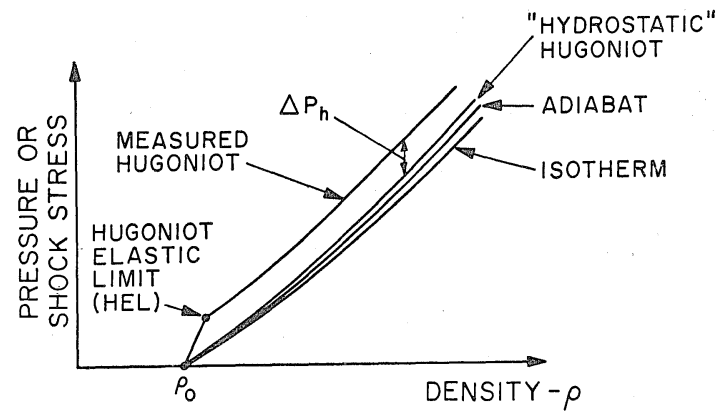

Fig. 2. Pressure or shock stress-density relation for material exhibiting strength effects under shock compression. Measured Hugoniot is offset by a stress, $\Delta P_{h}$, above 'hydrostatic' Hugoniot. 'Hydrostatic' Hugoniot would be measured if material retained zero strength upon shock compression.

In the present case these materials would include $\mathrm{MgO}, \mathrm{Al}_{2} \mathrm{O}_{3}$, and possibly $\mathrm{MnO}_{2}$ (Table 6).

Although some initial measurements of $P_{h}$ and $P_{p}$ in geologic materials shocked to high pressure are now being made (C. Godfrey, private communication), for the present purposes we have assumed that $\mathrm{Al}_{2} \mathrm{O}_{3}$ and $\mathrm{MgO}$ behave as simple elastoplastic materials. In such materials the maximum shear stress $\tau_{m}$ remains at the constant level which is achieved at the Hugoniot elastic limit. The Hugoniot elastic limit will thus define the maximum shear stress that the material can withstand under one-dimensional compression without internal rearrangement taking place at the shock front. The stress offset, calculated from the value of $\tau_{m}$ at the Hugoniot elastic limit for $\mathrm{Al}_{2} \mathrm{O}_{3}$ ceramic and for crystaldensity polycrystalline $\mathrm{Al}_{2} \mathrm{O}_{3}$, is 40 and $52 \mathrm{~kb}$, respectively. When these stress offsets are subtracted (at a given density) from the pressures along the Hugoniot, the resulting adiabats obtained from the 'hydrostatic' Hugoniot almost coincide with Perez-Albuerne and Drickamer's [1965] hydrostatic X-ray data for $\mathrm{Al}_{2} \mathrm{O}_{3}$ [Ahrens et al., 1968]. By applying this correction to the $\mathrm{Al}_{2} \mathrm{O}_{3}$ data over the entire pressure range and a similar correction of $\Delta P_{h}=15 \mathrm{~kb}$ for $\mathrm{MgO}$ (based on a minimum value of the HEL of $37 \mathrm{~kb}$ [Ahrens, 1966], the set of corrected equations of state parameters given in Table 6 is obtained.

Rather than introduce a strength correction in $\mathrm{MgO}$, Thomson [1969] has fit the shock data at high pressures and the ultrasonic data at low pressures by using a three-parameter equation of state. Although there is little doubt that a strength correction is required for $\mathrm{Al}_{2} \mathrm{O}_{3}$, the validity of the strength correction procedure for $\mathrm{MgO}$ is less clear. The reduced shock-wave data for $\mathrm{MgO}$ and $\mathrm{Al}_{2} \mathrm{O}_{3}$ also compare favorably with adiabats calculated from the Birch-Murnaghan parameters obtained in the ultrasonic experiments (Table 6, Figure 3-5). This result implies that, if the pressure-volume curves for these materials can be described by the Birch-Murnaghan equation, they do not undergo important phase changes over the pressure range of the shock data (this point is discussed 
below) and also that they support significant levels of shear stress at stresses well above 150 and $300 \mathrm{~kb}$.

The effective errors or uncertainties in the determination of the mean atomic weight $\bar{M}$ are also reflected in the determination of the equation of state parameters of the hpp, as can be seen from Table 7. Errors of 1 to $2 \%$ in the determination of $\bar{M}$ produce uncertainties of a similar magntiude in the calculated zero-pressure densities. For Montana bronzitite and Twin Sisters dunite we have used the analyses listed by Birch [1961], which are more accurate (McQueen, private communication) than those listed in McQueen et al. [1967b].

Since the equilibrium pressure required to transform the starting material to the appropriate hpp is only approximately known, the transition energies $E_{\text {tr }}$ required in equation 12 are poorly determined. Fortunately, uncertainties of the order of $50 \%$ in $E_{\text {tr }}$ result in uncertainties in the calculated zero-pressure densities of normally less than $1 \%$. This can be seen in Table 8 for transformation in the feldspars. For $\mathrm{MgO}$ and $\mathrm{Al}_{2} \mathrm{O}_{3}$ the transition energies are assumed to be zero, although the existence of a small energy difference resulting from a phase change accompanied by a small change in volume cannot be completely ruled out. For quartz transforming directly to stishovite, the thermochemical data of Holm et al. [1967] give a value of $\sim 12 \mathrm{kcal} / \mathrm{mole}$. This value was used as a lower bound in estimating some of the other transition energies for open-structured silicates and oxides. For andalusite and sillimanite we have assumed, for the present purposes, that these minerals break down to corundum and stishovite (see discussion in next section) and have used the appropriate thermochemical data given by Fyfe [1967]. The transition energy of microcline, which is presumed to transform to the hollandite structure, was estimated from the transition pressure measured by Ringwood et al. [1967b]. The values of $E_{\mathrm{tr}}$ for the other feldspars were obtained by using results for $\mathrm{KAlSi}_{3} \mathrm{O}_{8}$ and the estimated transition energies of the transformations for the reactions

and

$$
\begin{aligned}
& 2 \mathrm{NaAlSiO}_{4} \rightarrow \mathrm{NaAlSi}_{2} \mathrm{O}_{6}+\mathrm{NaAlO}_{2} \\
& \text { (nepheline) (jadeite) }
\end{aligned}
$$

$$
\underset{\text { (leucite) }}{3 \mathrm{KAlSi}_{2} \mathrm{O}_{6}} \rightarrow \underset{\text { (hollandite) }}{\mathrm{KAlSi}_{3} \mathrm{O}_{8}}+\mathrm{KAlO}_{2}
$$

\begin{tabular}{|c|c|c|c|c|c|c|c|}
\hline & $\begin{array}{c}\text { Mean } \\
\text { Atomic } \\
\text { Weight } \\
\bar{M}, \\
\mathrm{~g} / \mathrm{mole}\end{array}$ & $\begin{array}{c}\text { Density } \\
\rho_{0} \\
\mathrm{~g} / \mathrm{cm}^{3}\end{array}$ & $\begin{array}{c}\text { Grüneisen's } \\
\text { Ratio, } \\
\text { go }\end{array}$ & $\begin{array}{c}\text { Debye } \\
\text { Temperature } \\
\theta_{0}, \\
{ }^{\circ} \mathrm{K}\end{array}$ & $\begin{array}{c}\text { Bulk } \\
\text { Modulus } \\
K_{0 s} \\
\mathrm{~kb}\end{array}$ & $\xi_{8}$ & $K_{0 s^{\prime}}$ \\
\hline Twin Sisters & $20.90^{a}$ & 4.121 & 0.82 & 676 & 3267 & 1.01 & 2.65 \\
\hline Twin Sisters & 21.10 & 4.100 & 0.88 & 672 & 3105 & 0.931 & 2.76 \\
\hline Bronzitite & $21.2^{a}$ & 3.739 & 0.74 & 613 & 2117 & 1.14 & 2.48 \\
\hline Bronzitite & 20.68 & 3.822 & 0.60 & 627 & 2481 & 1.36 & 2.19 \\
\hline
\end{tabular}

TABLE 7. Effect of Uncertainty of Mean Atomic Weight

${ }^{a}$ Preferred value. 
TABLE 8. Effect of Varying Transformation Energy

\begin{tabular}{lcccccc}
\hline Starting Material & $\begin{array}{c}E_{\mathrm{tr}}, \\
10^{10} \mathrm{ergs} / \mathrm{g}\end{array}$ & $\begin{array}{c}\rho_{0}, \\
\mathrm{~g} / \mathrm{cm}^{3}\end{array}$ & $\gamma_{0}$ & $\begin{array}{c}K_{0 s}, \\
\mathrm{~kb}\end{array}$ & $\xi_{8}$ & $K_{08}$ \\
\hline Anorthosite & $0.86^{a}$ & 3.71 & 0.70 & 2084 & 1.203 & 2.40 \\
Anorthosite & 0.62 & 3.73 & 0.67 & 2158 & 1.23 & 2.35 \\
Oligoclase & $0.97^{a}$ & 3.69 & 1.0 & 2198 & 1.60 & 1.87 \\
Oligoclase & 0.57 & 3.70 & 0.62 & 2243 & 1.31 & 2.25 \\
Albitite & $0.99^{a}$ & 3.81 & 1.0 & 2550 & 1.63 & 1.82 \\
Albitite & 0.56 & 3.80 & 0.72 & 2448 & 1.16 & 2.45 \\
\hline
\end{tabular}

${ }^{a}$ Preferred value.

that have been obtained by Ringwood et al. [1967b]. For ferromagnesium minerals, complex oxides, and spinels the transformation energies were estimated by using the transformation energies for breakdown to the dense component oxides. For minerals such as $\mathrm{Fe}_{2} \mathrm{O}_{3}$ the transformation energy obtained by this method is probably too large. Instead we used the break in the Hugoniot data to indicate the thermodynamic pressure of transition as described by $M c Q u e e n$ et al. $[1963,1967 b]$. Of course, if the mineralogy of the mantle were known, the energies of the ferromagnesium minerals might be inferred from the seismic velocitydepth profiles.

Over the range of the present data for the high-pressure phases, the compressions are generally less than 0.6 . As can be seen from Table 8 , large variations in the value used for the zero-pressure Grüneisen's ratio in the reduction of the shock-wave data affect the inferred zero-pressure density and the parameters of the equation of state of the high-pressure phases to only a minor degree. In Table 9 the parameters of the equation of state are calculated by using both the Dugdale-MacDonald (equation 8) and the Slater relations (equation 9) for the zero-pressure Grüneisen ratio. The results for $\mathrm{Fe}_{3} \mathrm{O}_{4}$ are particularly striking in that a $60 \%$ change in the zero-pressure Grüneisen ratio from the Dugdale-

TABLE 9. Effect of Varying Grüneisen's Ratio

\begin{tabular}{|c|c|c|c|c|c|}
\hline Material & $\gamma_{0}^{*}$ & $\begin{array}{c}\rho_{0}, \\
\mathrm{~g} / \mathrm{cm}^{3}\end{array}$ & $\begin{array}{c}K_{03}, \\
\mathrm{~kb}\end{array}$ & $\xi_{s}$ & $K_{0 s^{\prime}}$ \\
\hline $\mathrm{Al}_{2} \mathrm{O}_{3}$, crystal & $1.1 \quad(\mathrm{D}-\mathrm{M}) \dagger$ & 3.938 & 2931 & 0.66 & 3.12 \\
\hline $\mathrm{Al}_{2} \mathrm{O}_{3}$, crystal & $1.4 \quad(\mathrm{~S}) \dagger$ & 3.934 & 3917 & 0.69 & 3.09 \\
\hline $\mathrm{Al}_{2} \mathrm{O}_{3}$, ceramic & $1.1 \quad(\mathrm{D}-\mathrm{M}) \dagger$ & 4.040 & 3255 & 0.64 & 3.15 \\
\hline $\mathrm{Al}_{2} \mathrm{O}_{3}$, ceramic & $1.4 \quad(\mathrm{~S}) \dagger$ & 4.044 & 3266 & 0.71 & 3.05 \\
\hline $\mathrm{Fe}_{3} \mathrm{O}_{4}$ & $0.39(\mathrm{D}-\mathrm{M}) \dagger$ & 6.299 & 4488 & 1.66 & 1.79 \\
\hline $\mathrm{Fe}_{3} \mathrm{O}_{4}$ & $0.63(\mathrm{~S}) \dagger$ & 6.321 & 4553 & 1.80 & 1.59 \\
\hline $\mathrm{Fe}_{3} \mathrm{O}_{4}$ & $0.37(\mathrm{D}-\mathrm{M}) \ddagger$ & 6.298 & 4481 & 1.70 & 1.74 \\
\hline Twin Sisters dunite & $0.76(\mathrm{D}-\mathrm{M}) \ddagger$ & 4.11 & 3240 & 1.11 & 2.52 \\
\hline Twin Sisters dunite & $0.82(\mathrm{D}-\mathrm{M} \mathrm{M}) \dagger$ & 4.11 & 3267 & 1.01 & 2.65 \\
\hline
\end{tabular}

* Value at $P=0 ;(\mathrm{S})=$ Slater relation, $(\mathrm{D}-\mathrm{M})=$ Dugdale-McDonald relation.

$+\gamma / V=$ constant.

$\ddagger \gamma=$ constant. 
MacDonald value of 0.39 to the Slater value of 0.63 changes the resulting zeropressure density from 6.299 to $6.321 \mathrm{~g} / \mathrm{cm}^{3}$ and the zero-pressure bulk modulus from 4488 to $4553 \mathrm{~kb}$.

The sensitivity of the reduction of shock-wave data to the assumed volume dependence of the Grüneisen ratio was also examined, since this has been a subject of considerable discussion in the literature [Rice et al., 1958; Alder, 1966; Anderson, 1968]. Since most of the present computations were performed with $\gamma / V=$ constant, which implies a decrease in $\gamma$ with compression, we consider it important to test a wide variation from this assumption. We note also that the sensitivity of the calculation on the dependence of $\gamma$ with compression is expected to be greater for materials that undergo a large shock-induced volume change. To test the effect of varying the compression dependence of Grüneisen's ratio on our calculations, we assumed that $\gamma=$ constant for several materials that undergo major shock-induced phase changes. The results obtained for $\mathrm{Fe}_{3} \mathrm{O}_{4}$ and Twin Sisters dunite, when the zero-pressure values of $\gamma$ are calculated from the Dugdale-MacDonald relation and held constant, are given in Table 9. As can be seen the effect of varying the compression dependence of $\gamma$ is small when compared with the effect of assuming different values for $\gamma_{0}$, i.e., the Slater relation versus the Dugdale-MacDonald relation. These results, however, should be taken with some caution, as a recent recalculation of the shock data for stishovite using measured values of Grüneisen's ratio gave values for $K_{0 s}$ and $K_{0 s}$ ' of $3000 \mathrm{~kb}$ and 7 [Ahrens et al., 1969b].

\section{PARAMETERS OF HIGH-PRESSURE EQUATION OF STATE}

The derived pressure-density curves for several materials of importance to the earth's interior are shown in Figures 3-9. For the materials that undergo a shock-induced phase change at a given density, the Hugoniot centered at the initial state lies at a considerably higher pressure than the computed metastable Hugoniot $(m)$, adiabat $(s)$, and isotherm $(t)$ of the hpp. For $\mathrm{MgO}$ and $\mathrm{Al}_{2} \mathrm{O}_{3}$, when they are assumed to have their normal zero-pressure densities and are corrected for strength effects (Figures 3-5), the shock data yield bulk moduli and $(d K / d P)$ values (Table 6$)$ that are in good agreement with recent ultrasonic determinations. The earlier correlation [Anderson, 1965b] of the shock and ultrasonic data for $\mathrm{MgO}$ appears to have been fortuitous, since the ultrasonic bulk moduli of $\mathrm{MgO}$ was too high ( $1717 \mathrm{~kb}$ versus the present value $1622 \mathrm{~kb})$. (The effect of a decreasing $K_{0 s}^{\prime}$ with compression was probably less important in the correlation.) It is interesting that the high value previously assumed for the bulk modulus of $\mathrm{MgO}$ in the earlier correlation appears to have been largely offset by the correction for strength effects. A near-zero value of the BirchMurnaghan parameter $\xi$ for $\mathrm{MgO}$ (Figure 10) agrees with the result recently obtained by Wang [1968]. For single-crystal $\mathrm{Al}_{2} \mathrm{O}_{3}$ the correlation of shock and ultrasonic data is improved over that given by Anderson [1965b] in that the 52 -kb strength-effect correction reduces the apparent bulk modulus of the shock data. Correlation of the shock and ultrasonic data is also improved for the $\mathrm{Al}_{2} \mathrm{O}_{3}$ ceramic, because the present analysis takes into account the slight initial porosity of the ceramic which has the effect of increasing the bulk modu- 
Fig. 3. Least squares BirchMurnaghan fits to raw $\mathrm{Hu}$ goniot data (dashed curve) for $\mathrm{MgO}$ [McQueen et al., 1967b]. Points are data corrected for one-dimensional strength effects, and 'hydrostatic' $\mathrm{Hu}-$ goniot is the corresponding least-squares fit. Adiabat and $25^{\circ} \mathrm{C}$ isotherm are computed (see text). Crosses are adiabat points calculated from ultrasonic data on $\mathrm{MgO}$ reported by Anderson et al. [1968] using Birch-Murnaghan equation (see Table 6).

Fig. 4. Least squares BirchMurnaghan fits to raw $\mathrm{Hu}-$ goniot, corrected 'hydrostatic' Hugoniot, and calculated metastable Hugoniot, adiabat, and isotherm for ceramic $\mathrm{Al}_{2} \mathrm{O}_{3}$. Crosses are adiabat points ex-. trapolated via Birch-Murnaghan equation from low-pressure ultrasonic data of Anderson et al. [1968] (see Table 6). (Data from McQueen and Marsh [1966] and Ahrens et al. [1968].)
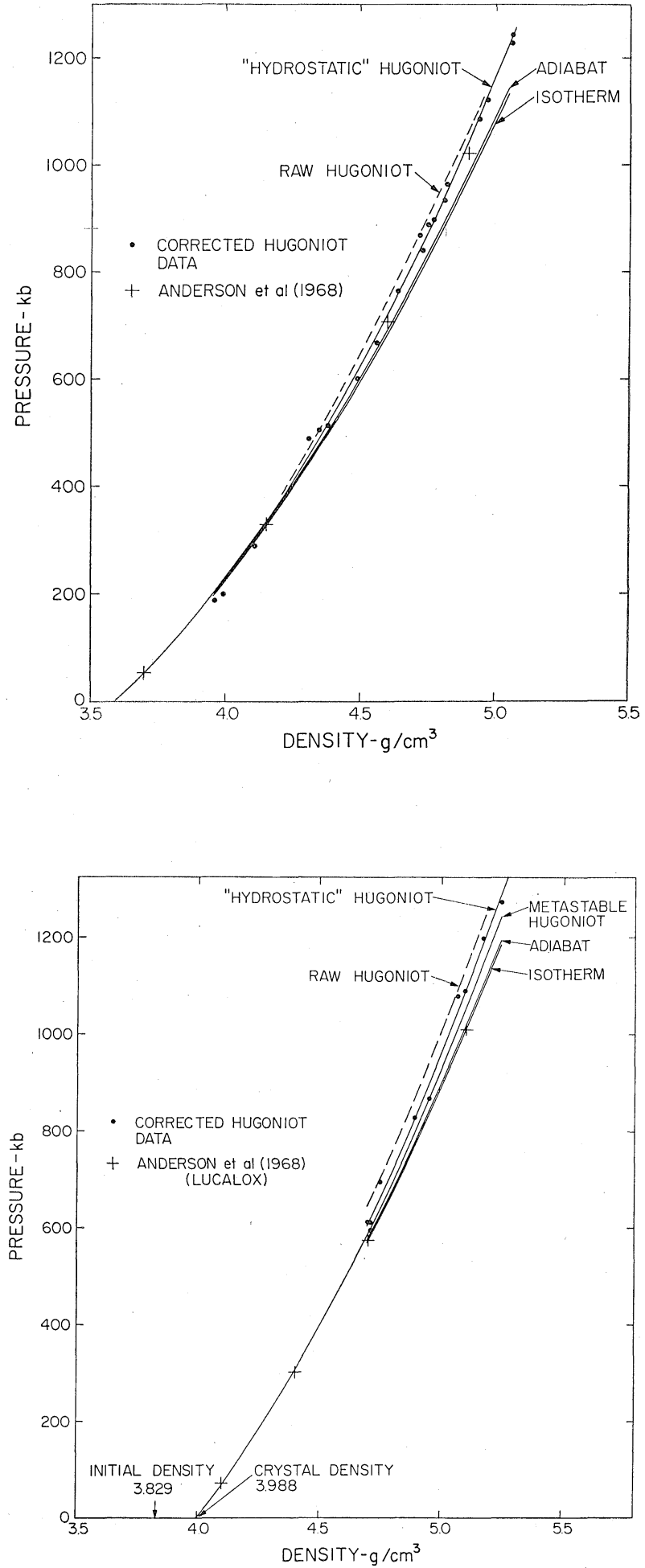


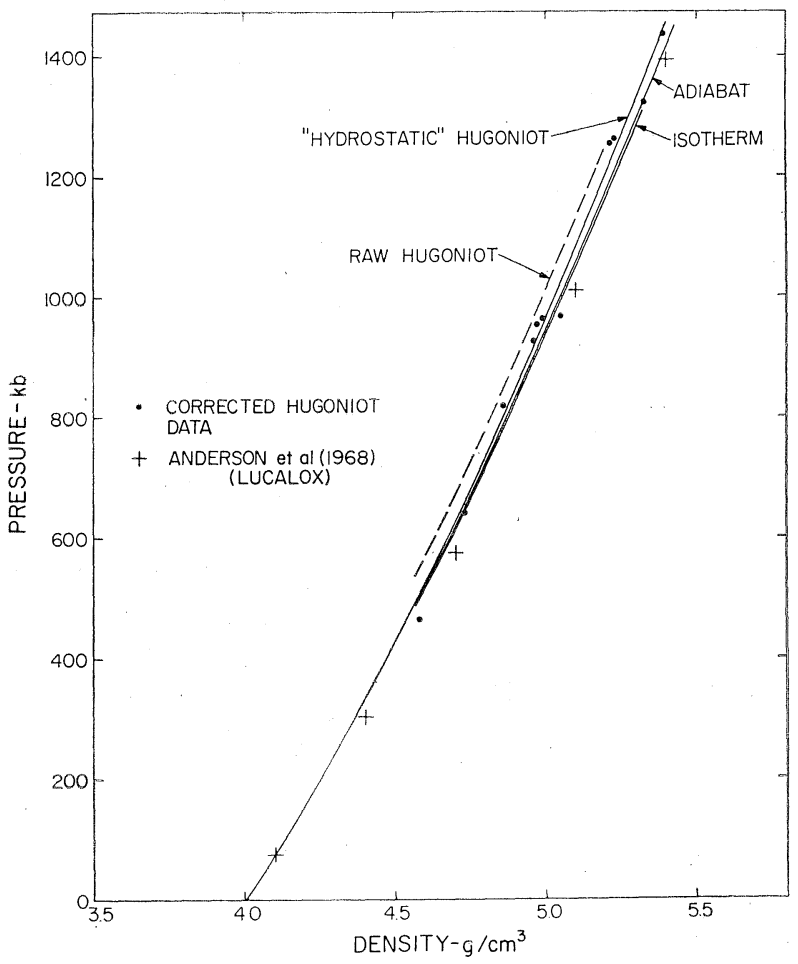

Fig. 5. Fitted raw and 'hydrostatic' Hugoniots and calculated adiabat and isotherm for single crystal $\mathrm{Al}_{2} \mathrm{O}_{3}$. Dashed curves, points, and crosses have same meaning as in Figure 4.

(Data from McQueen and Marsh [1966].)

lus value, making it quite comparable to ultrasonic data for polycrystalline $\mathrm{Al}_{2} \mathrm{O}_{3}$. The importance of the second-order parameter $\xi$, or $B / A$, of equation 3 in the Birch-Murnaghan equation is illustrated in Figure 10 and Table 3 . As can be seen, the oxides $\mathrm{MgO}$ and $\mathrm{Al}_{2} \mathrm{O}_{3}$ have $\xi \approx 0$. This corresponds to values of $K_{0 s}{ }^{\prime} \approx 4$. The values obtained for stishovite are $\xi=0.73$ and $K_{0 s}{ }^{\prime}=3.03$ (new calculations by Ahrens et al. [1969a] using measured Grüneisen ratios give

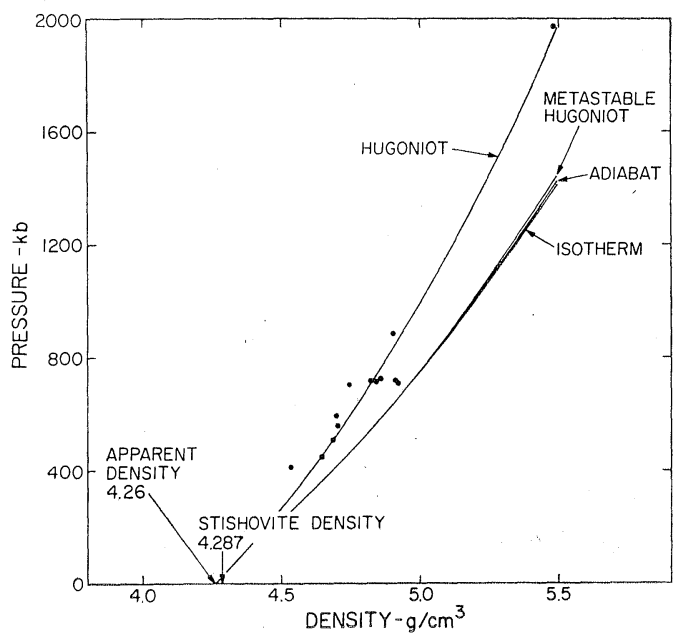

Fig. 6. Hugoniot data obtained by shocking $\alpha$-quartz [Wackerle, 1962; Al'shuler et al., 1966]. Curve labeled 'Hugoniot' is a Birch-Murnaghan leastsquares fit to these data. Also shown are calculated curves for metastable $\mathrm{Hu}$ goniot, $25^{\circ} \mathrm{C}$ isotherm, and adiabat, centered at room temperature. These are believed to represent behavior of stishovite [McQueen et al., 1963]. 


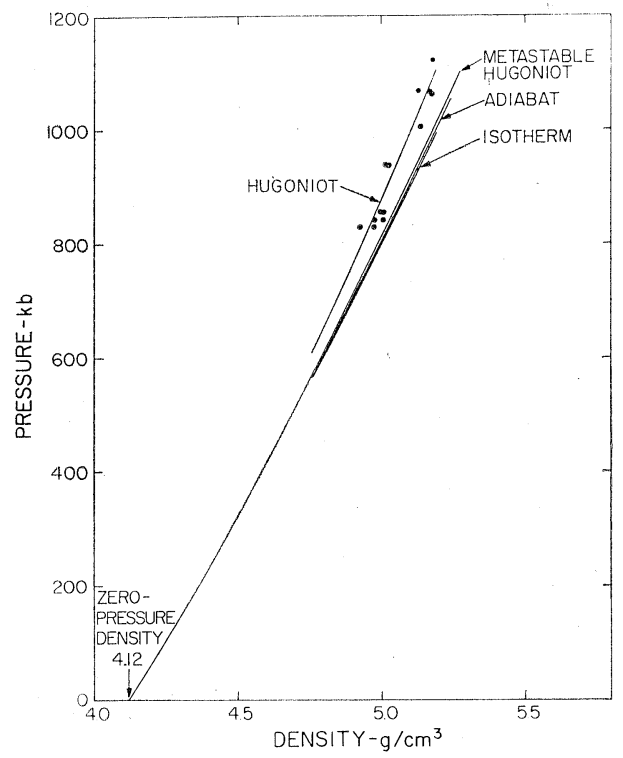

Fig. 7. High-pressure phase (hpp) points for Twin Sisters dunite and fitted BirchMurnaghan equation of state. Also shown are room temperature metastable Hugoniot, adiabat, and isotherm. (Data from $M c$ Queen et al. [1967b].)

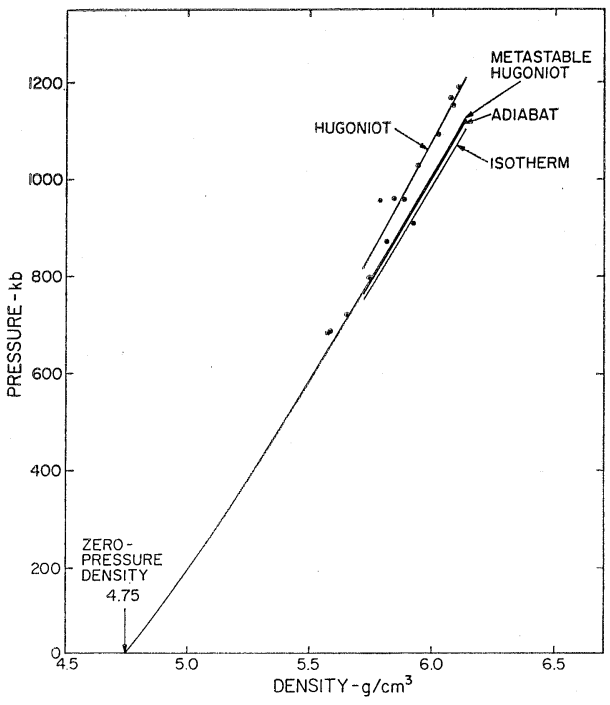

Fig. 8. hpp points for iron-rich (hortonolite) dunite and fitted Birch-Murnaghan equation of state. Also shown are calculated metastable Hugoniot, adiabat, and isotherm centered at room temperature.

(Data from McQueen et al. [1967b].)
Fig. 9. hpp points for bronzitite and fitted Hugoniot. Also shown are calculated metastable Hugoniot, adiabat, and isotherm, all centered at room temperature. (Data from $M c$ Queen et al. [1967b].

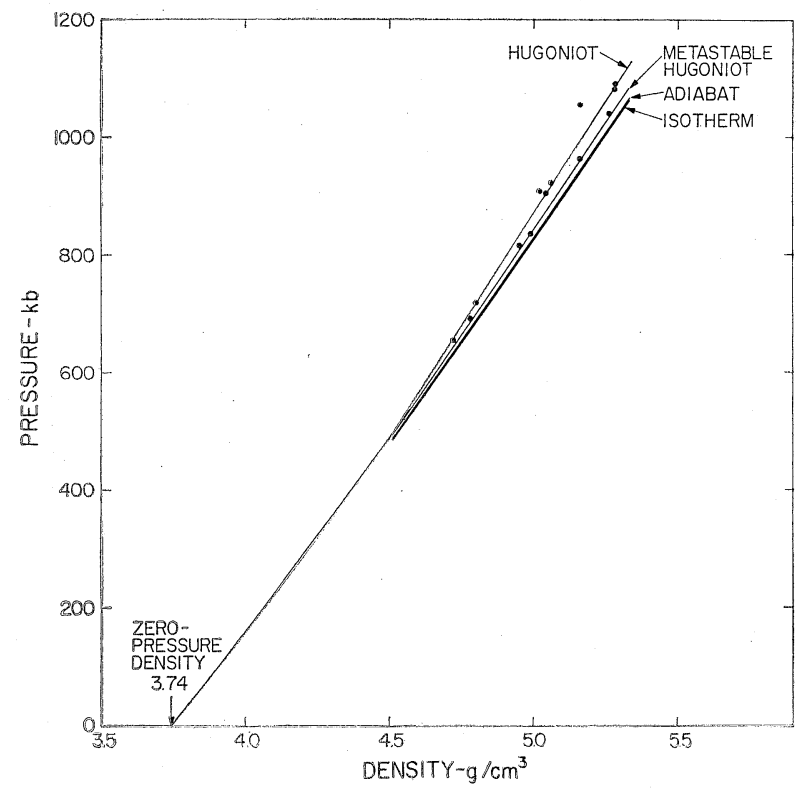




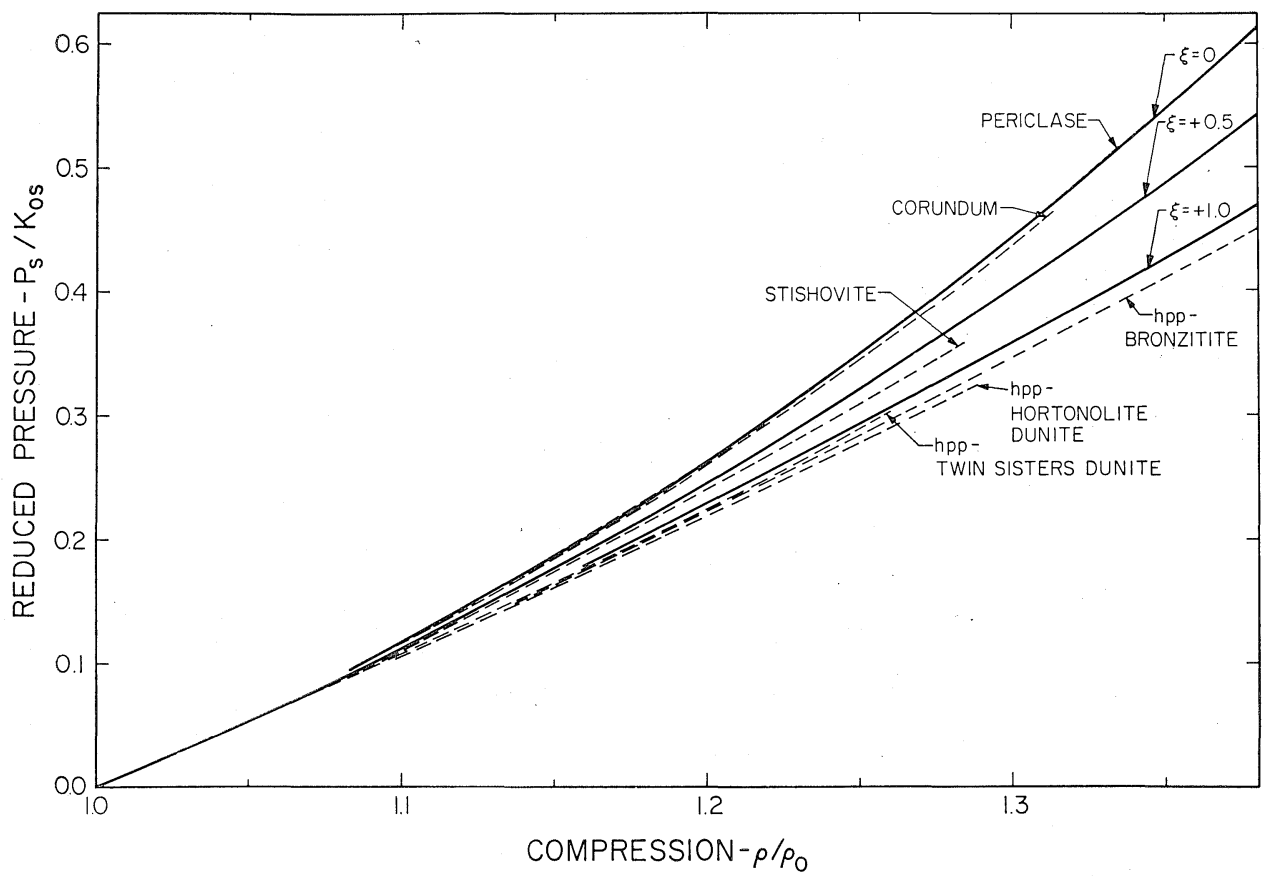

Fig. 10. Compression $\left(\rho / \rho_{0}\right)$ versus reduced pressure $\left(P / K_{0}\right)_{s}$ representing Birch-Murnaghan fits to the calculated adiabats for some of the materials studied in this paper. Also shown are loci for three values of $\xi$ in Birch-Murnaghan relation.

$K_{o s}{ }^{\prime}=7$ ), whereas the high-pressure phases of olivine and pyroxenes have values of $\xi$ closer to 1 with $K_{0 s}{ }^{\prime}$ between 2 and 3.

The zero-pressure values of $K_{0 s}$, or $\Phi_{s}$, for the high-pressure phases have been fixed by means of the relation given by equation 10. It is of interest to examine how the bulk modulus, or $\Phi$, varies with increase in density on compression. As can be seen in Figure 11, all the derived adiabats deviate upward from the line given by

$$
\rho / \bar{M}=0.048 \Phi^{0.323}
$$

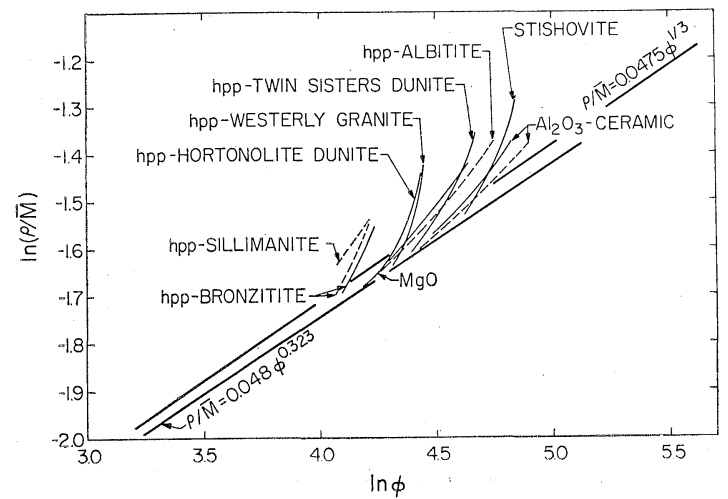

Fig. 11. Relationship between In $(\rho / \bar{M})$ and $\ln \Phi$ along adiabat (solid lines) and along Hugoniot (dashed lines) for some of materials studied. In the reduction scheme, all materials are required to fall on the line $\rho / \bar{M}=$ $0.048 \Phi^{0.323}$ at $P=0$. Line $\rho / \bar{M}=$ $0.0475 \Phi^{1 / 3}$ was used in reduction scheme of Anderson and Kanamori [1968]. 
which indicates that $d K / d P$, calculated along the adiabats and the Hugoniot, decreases with compression (see also Table 2). The hpp's of the silicates demonstrate a similarity (Figure 12) in the variation of the $K_{0 s}{ }^{\prime}$ parameter with compression. This is, of course, a consequence of employing the Birch-Murnaghan equation for an equation of state. We note that they all have $\left(d K_{0 s}{ }^{\prime} / d_{\rho}\right)_{s}$ values of -0.5 to $-0.7 \mathrm{~cm}^{3} / \mathrm{g}$. Furthermore, the variation of $K_{0 s^{\prime}}$ with density seems to have a similar value of $\left(d K_{0 s}{ }^{\prime} / d_{\rho}\right)_{s}$ when the density is changed on substitution of iron. When going from $\mathrm{MgO}$ to $\mathrm{FeO}$, a slope of $-0.3 \mathrm{~cm}^{3} / \mathrm{g}$ is obtained, whereas, when going from the hpp's of Twin Sisters dunite to Hortonolite dunite to Rockport fayalite, $\left(d K_{0 s}{ }^{\prime} / d_{\rho}\right)_{s}$ values of -0.4 and $-1.6 \mathrm{~cm}^{3} / \mathrm{g}$ are obtained. (The value of $K_{0 s}$ ' for the Rockport fayalite should be viewed with some suspicion, since it is based on only 5 Hugoniot points in the high-pressure regime.) We note that the theoretical lower limit of $5 / 3$ for $K_{0 s}{ }^{\prime}$ is obtained from the ThomasFermi theory [see, for example. Knopoff, 1965]. The reduced data for some

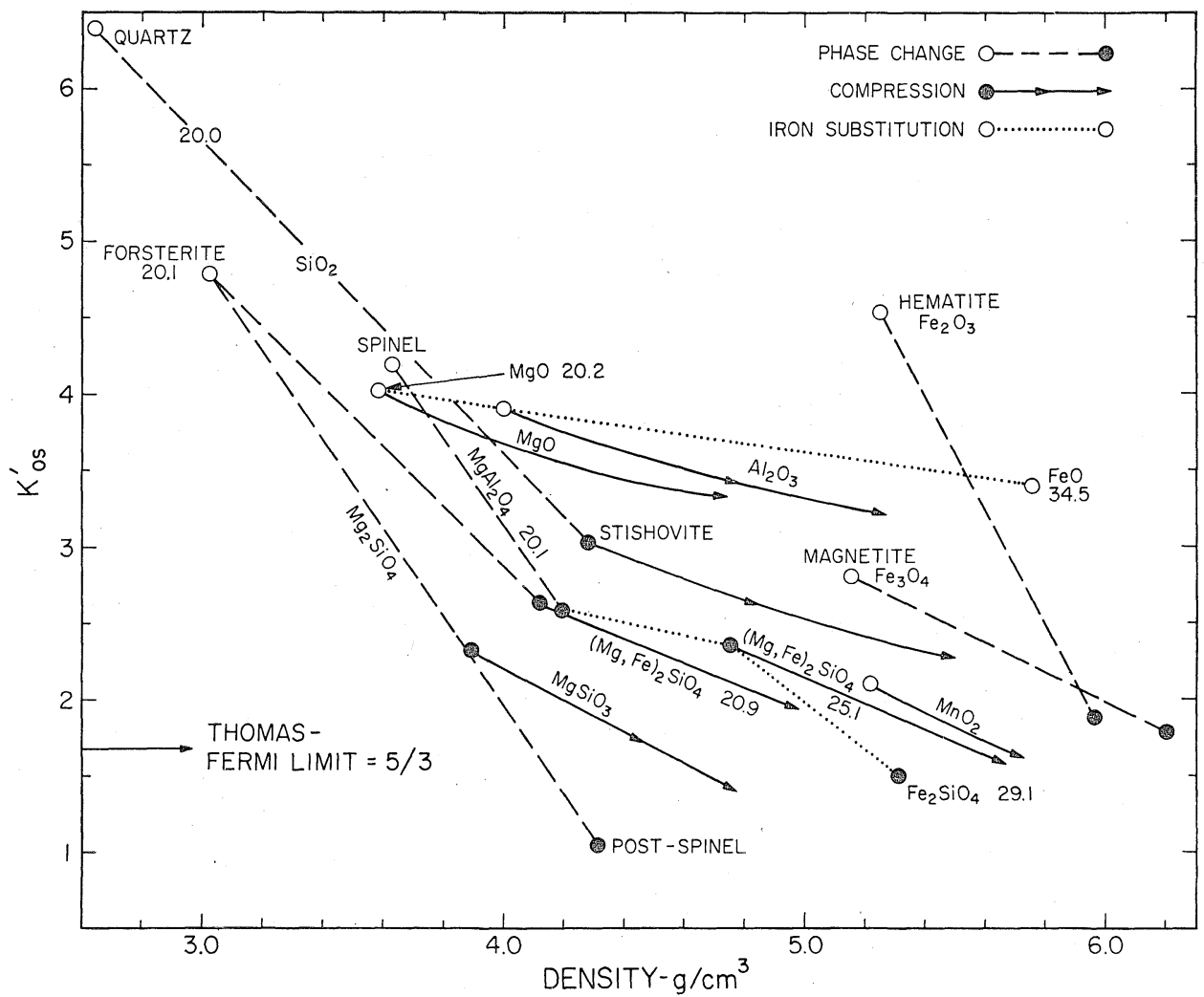

Fig. 12. Pressure derivative of adiabatic bulk modulus at zero pressure $\left(K_{0 s}{ }^{\prime}\right)$ versus density for low-pressure phases (open circles) and high-pressure phases (closed circles). Note the general tendency of $K_{0 s}{ }^{\prime}$ to decrease with density for both iron substitution and phase changes. The solid lines with arrows indicate the trajectories of $K_{s}^{\prime}$ versus $\rho$ for compression implied by Birch-Murnaghan equation. Low-pressure data from Anderson et al. [1968] [quartz, forsterite, spinel, $\mathrm{MgO}, \mathrm{Al}_{2} \mathrm{O}_{3}$ ], England and Simmons (personal communication) [ $\left[\mathrm{Fe}_{3} \mathrm{O}_{4}\right]$ and Clendenen and Drickamer [1966] [FeO]. 
of the higher-density compounds, such as $\mathrm{MnO}_{2}$ and the high-pressure phases of the olivines, suggest that $K_{0 s}{ }^{\prime}$ values lower than $5 / 3$ may occur, although uncertainties both in the data and in the analysis make this point unclear. On passing through a phase transition, the values of $K_{0 s}^{\prime}$ also decrease with increasing density. The value of the ratio $\Delta K_{0 s}{ }^{\prime} / \Delta \rho$ through a phase transition varies from -2.1 , for quartz to stishovite, to $-3.7 \mathrm{~cm}^{3} / \mathrm{g}$, for normal $\mathrm{Fe}_{3} \mathrm{O}_{4}$ to hpp $\mathrm{Fe}_{3} \mathrm{O}_{4}$.

Since the Grüneisen ratio is related to $K_{0 t}{ }^{\prime}$ by

$$
\gamma_{\mathrm{DM}}=\left(K_{0 \mathrm{t}}{ }^{\prime} / 2\right)-\frac{1}{2}
$$

and

$$
\therefore \gamma_{\mathrm{s}}{ }^{\mathrm{F}}=\left(K_{0 s^{\prime}} / 2\right)-\frac{1}{6}
$$

the systematics that apply to $K_{0 s}{ }^{\prime}$ or $K_{0 t^{\prime}}$ should also apply to $\gamma_{\mathrm{DM}}$ or $\gamma_{\mathrm{s}}$. Hence, if the Slater or Dugdale-MacDonald theory is valid, the Grüneisen ratio of the high-pressure phase will generally be lower than the value for the zero-pressure phase material. We also note (Table 3) that the Grüneisen ratio of the hpp decreases with increasing iron content.

\section{NATURE OF HIGH-PRESSURE PHASES}

In most of the cases previously discussed, there was clear evidence that major phase changes occurred at shock pressures of a few hundred kilobars. We now consider evidence relating to the nature of the high-pressure phases.

The maximum pressure obtainable by current static high-pressure temperature apparatus is in the vicinity of $200 \mathrm{~kb}$, which is lower than the pressures observed for most shock transformations in oxides and silicates. Consequently, only in rare cases (e.g., stishovite) is it possible to identify the shock highpressure phase with reasonable certainty by comparison with the known properties of a phase that has been synthesized under static conditions. Accordingly, identifications must be based on indirect evidence: for example, comparative crystal chemistry and static high-pressure studies of analog systems such as germanates. The classical rules of crystal chemistry explain the relative stabilities of ionic structures largely in terms of radius ratios and packing of constituent ions and from valence-bond and charge neutralization requirements. There are no grounds to suppose that these fundamental rules change at high pressure. Numerous static experiments show that there is a strong probability that a high-pressure phase will possess a structure that is already known to be adopted by many related compounds at atmosphere pressure (particularly for transformations involving large $(>5 \%)$ volume changes). Thermodynamic considerations dictate that the new structure be denser, and it will usually be found to be characterized by a different set of ionic radius ratios than those of the lowpressure structure. Specifically, the high-pressure structure tends to be characterized by a higher cation/oxygen radius ratio, which may be simply explained if it is assumed that the effective radius of the large oxygen anion (1.32 $\AA$ ). decreases relatively more with pressure than do the smaller cation radii. By means of crystal chemical systematics the relative densities of compounds in 
new possible high-pressure structures can be estimated [e.g., Reid and Ringwood, $1969 a]$, and the possibilities can be further restricted by consideration of radiusratio trends.

A second approach to structure prediction is based on static high-pressure studies of analog systems, particularly germanates. The crystal chemistry of germanates is very closely related to that of silicates [Goldschmidt, 1931]. Furthermore, germanates possess the very useful property of behaving as models for the corresponding silicate, since the germanates frequently display phase transformations similar to silicates but at much lower pressures [Ringwood, 1966]. Hence, studies of transformations in germanates using available static pressures yield information on the probable modes of transformation of corresponding silicates at much higher pressures, beyond the static range. Other classes of compounds, e.g. titanates, can also serve as models that can provide useful information on probable transformations in silicates [Ringwood et al., $1967 a ;$ Akimoto and Syono, 1967].

Frequent use of these indirect methods will be made in the following sections in order to infer the probable nature of shock phases. The uncertainties inherent in this approach should not be ignored. In static high-pressure studies of phase changes accompanied by large volume changes in silicates, a significant proportion of the transformations are to structures that do not have germanate analogs and that may be of an entirely unknown type. Since it is reasonable to expect that some of the shock-wave transformations belong to this class, such transformations are accordingly intrinsically unpredictable by these methods.

Under the usual conditions employed in experimental shock-wave investigations, the properties of the specimen are measured as the shock wave propagates through it. This propagation occurs in a period that is usually less than a microsecond. This period is extremely small as compared with the times required for attainment of equilibrium in most oxides and silicates under static high-pressure high-temperature conditions (usually periods of minutes to hours). Although the intense shear and high temperature associated with the shock undoubtedly speeds up the reaction rate, it appears likely that chemical equilibrium will not be reached under shock conditions in many cases. For example, the known transformations of olivine to spinel structure have not been observed under shock conditions. Furthermore, the pressures at which many transformations (e.g., stishovite) are completed under shock conditions appear to be much higher than the probable equilibrium pressures as inferred from static high-pressure and high-temperature experiments, thermodynamic considerations, and geophysical data. In most shock experiments on oxides and silicates it appears necessary to overstress the specimen far beyond the equilibrium transformation pressure before transformation becomes complete. We must therefore consider the kinetic factors involved in the possible transformations when interpreting the results.

In addition to the above considerations, with many of the materials under study, more than one structural state is possible for a hpp. These states may be separated by relatively small energy differences. Which of these states is finally achieved under shock may be controlled dominantly by the kinetics involved rather than by equilibrium considerations. This applies particularly 
to cases in which one possible structural state possesses an identical stoichiometry to the starting material, e.g., quartz $\rightarrow$ coesite $\rightarrow$ stishovite, whereas the other possible states represent a disproportionation into two or more phases, isochemical in bulk with the starting material, e.g., albite $\rightarrow$ jadeite + stishovite, or forsterite $\rightarrow$ periclase + stishovite. In general, one might intuitively expect that the problems of nucleation and grain growth into two or more phases during the sub-microsecond period of a shock would make this kind of transformation less probable than an iso-stoichiometric transformation in which the atoms must move over distances of the order of a few angstrom units in order to reach the lattice sites appropriate for the hpp. Nevertheless, in cases for which a suitable iso-stoichiometric structure does not exist, or for which the structure is very much less stable than an isochemical mixture of phases, disproportionation into two phases must still be considered a possibility.

The interpretation that follows applies principally to data on minerals and rocks that were analyzed earlier in this paper. In addition, we will also discuss the probable high-pressure states of two basalts and a rutile for which the zeropressure densities were obtained by Anderson and Kanamori [1968] on the basis of raw Hugoniot data.

If we assume that the raw experimental data used in the reductions refer to conditions of compression of a homogeneous phase or phase assemblage and that the related proportions of these phases do not change with pressure, the derived low-pressure density should be correct to about 5\%, exclusive of possible errors in experimental data. On the other hand, there is always the possibility that in the pressure range investigated, conversion to the high-pressure phases was incomplete. (This appears to be the case, for example, for the McQueen et al. [1967b] data for Healdburg eclogite.) If, as seems likely, the degree of conversion to the high-pressure state increases with pressure, a given set of data would yield an anomalously high compressibility. The use of this anomalous compressibility in the reduction method would yield a low-pressure density of the shocked phase that is smaller than the correct value. Since in some cases there was clear evidence that this had in fact occurred, further discussion is not warranted. There are in addition a few cases (e.g., bronzitite, microcline, and anorthosite) in which this type of behavior is suspected but cannot be definitely established. In such cases we should emphasize that the derived lowpressure density is likely to be a lower limit.

\section{Behavior of Simple Oxides under Shock Compression}

Transformations were observed in $\mathrm{SiO}_{2}, \mathrm{TiO}_{2}$, and $\mathrm{Fe}_{2} \mathrm{O}_{3}$ but were not observed in $\mathrm{Al}_{2} \mathrm{O}_{3}, \mathrm{MgO}, \mathrm{MnO}_{2}$, and $\mathrm{SnO}_{2}$. The reduced zero-pressure density for $\mathrm{Al}_{2} \mathrm{O}_{3}$ (Table 3) as calculated from the high-pressure shock data is in excellent agreement with its true value. The reduced zero-pressure density for $\mathrm{MgO}$ is slightly higher than the true value and, interpreted literally, might be taken as evidence of transformation to a denser phase (e.g., cesium chloride structure). Although this possibility cannot be dismissed, we do not believe that the conclusion is justified since, if the data are constrained to have the periclase zeropressure density, excellent agreement with the ultrasonic bulk moduli and 
$\left(d K_{0 s} / d P\right)_{s}$ is obtained (Table 6). The inferred zero-pressure densities of $\mathrm{MnO}_{2}$ and $\mathrm{SnO}_{2}$ are in reasonable agreement with the true densities of these phases, considering the quality of the experimental data. Clendenen and Drickamer [1966] have observed the occurrence of 'apparent' phase transformations in these minerals under static high pressures. We conclude that the volume changes in these transformations are likely to be relatively small.

The transformation of $\mathrm{SiO}_{2}$ under shock conditions has been fully discussed by Wackerle [1962] and McQueen et al. [1963]. Their data, together with the recovery experiments of DeCarli and Milton [1965], provide strong evidence that the high-pressure phase produced during the shock was indeed stishovite. Our inferred zero-pressure density for shocked $\mathrm{SiO}_{2}$ is in excellent agreement with that of stishovite (Table 10). The behavior of titanium dioxide has been discussed by McQueen et al. [1967a], who concluded that transformation to a phase with a structure related to fluorite had occurred. Reduction of the shock data for rutile [Anderson and Kanamori, 1968] supports this interpretation (Table 10$)$. The large density increase $(\sim 30 \%)$ is caused by the increase in coordination of the titanium atom from 6 to 8 .

Syono and Akimoto [1968], having observed that $\mathrm{PbO}_{2}$, which has a rutile structure at low pressure, can be transformed into a fluorite structure under high pressure, suggest that stishovite may also transform to the fluorite structure at ultrahigh pressure. Fujisawa [1968] has suggested that the fluorite modification of $\mathrm{SiO}_{2}$ may be of significance in the earth's mantle. The shock data on $\mathrm{SiO}_{2}$ that extend to pressures greater than the pressures at the core-mantle boundary do not support this suggestion, since they imply that stishovite is stable over the entire pressure range. The pressures required to induce a small atom like $\mathrm{Si}^{+4}$ (radius $=0.42 \AA$ ) to transform from six-fold to eight-fold coordination with respect to oxygen are likely to be very much higher than the pressures required for the transformations of rutile and $\mathrm{PbO}_{2}$ to the fluorite structure $\left(\mathrm{Ti}^{+4}=0.68 \AA, \mathrm{Pb}^{+4}=0.84 \AA\right.$ ) (see Figure 13). Furthermore, it should be

TABLE 10. Interpretation of Zero-Pressure Densities and Structures of Some Simple Oxides under Shock

\begin{tabular}{|c|c|c|c|c|}
\hline $\begin{array}{c}\text { Initial } \\
\text { Density }\end{array}$ & Oxide & $\begin{array}{c}\text { Calculated } \\
\text { Zero-Pressure } \\
\text { Density of } \\
\text { Shocked Phase, } \\
\mathrm{g} / \mathrm{cm}^{3}\end{array}$ & $\begin{array}{c}\text { Inferred } \\
\text { Structure } \\
\text { of Shocked } \\
\text { Phase }\end{array}$ & $\begin{array}{c}\text { Structure } \\
\text { Density, } \\
\mathrm{g} / \mathrm{cm}^{3}\end{array}$ \\
\hline 3.99 & $\mathrm{Al}_{2} \mathrm{O}_{3}$ & $3.94^{a}, 4.04^{a}$ & Untransformed & $\ldots$ \\
\hline 3.58 & $\mathrm{MgO}$ & $3.70^{a}, 3.82^{a}$ & Untransformed & $\ldots$ \\
\hline 5.23 & $\mathrm{MnO}_{2}$ & 5.09 & Untransformed & $\ldots$ \\
\hline 6.99 & $\mathrm{SnO}_{2}$ & & Untransformed & $\ldots$ \\
\hline 4.25 & $\mathrm{TiO}_{2}$ & $5.71^{b}$ & Fluorite & 5.5 \\
\hline 2.65 & $\mathrm{SiO}_{2}$ & 4.34 & Stishovite & 4.28 \\
\hline 5.27 & $\mathrm{Fe}_{2} \mathrm{O}_{3}$ & 5.96 & Perovskite & 5.8 \\
\hline
\end{tabular}

a See Table 3.

${ }^{\circ}$ Calculation by Anderson and Kanamori [1968]. 
noted that neither $\mathrm{SnO}_{2}$ nor $\mathrm{MnO}_{2}$, each of which possesses rutile structures, transformed to the fluorite structure at pressures up to about $1 \mathrm{Mb}$. Both of these, because of their larger cation radii $\left(\mathrm{Sn}^{+4}=0.71 \AA, \mathrm{Mn}^{+4}=0.60 \AA\right.$ ), are likely to require lower pressures to transform to the fluorite structure than stishovite.

The transformation of hematite is of interest. We estimate a zero-pressure density for the high-pressure phase of $5.96 \mathrm{~g} / \mathrm{cm}^{3}$ compared with the normal density of hematite, $5.27 \mathrm{~g} / \mathrm{cm}^{3}$. Crystal chemical relationships among $R_{2} \mathrm{O}_{3}$ compounds with respect to high-pressure transformations have been investigated by Reid and Ringwood [1968]. They showed that compounds with the corundum structure are likely to transform either to the B rare earth structure (e.g., high-pressure $\mathrm{Sc}_{2} \mathrm{O}_{3}$ ) or to the perovskite structure (e.g., $\mathrm{YFeO}_{3}$ ) at high pressure. The $\mathrm{B}$ rare earth structure is monoclinic, and the cations are distributed among three crystallographically distinct sites, two with seven-fold coordination with respect to oxygen and one with six-fold coordination. This structure is about $5.5 \%$ denser than the corresponding corundum or ilmenite structure. The expected density of the hpp of hematite would accordingly be $5.56 \mathrm{~g} / \mathrm{cm}^{3}$, which is substantially lower than the inferred density of $5.96 \mathrm{~g} / \mathrm{cm}^{3}$. In the ideal (cubic) perovskite structure, half the $\mathrm{Fe}$ atoms would be in eight-fold and half in six-fold coordination. From the extrapolation of molar volume versus mean atom octahedral bond length for $R_{2} \mathrm{O}_{3}$ compounds, Reid and Ringwood [1968] inferred that the $\mathrm{Fe}_{2} \mathrm{O}_{3}$ perovskite would be about $10 \%$ denser than the corundum form, leading to a density of about $5.8 \mathrm{~g} / \mathrm{cm}^{3}$ for the hpp. This is in reasonable agreement with the zero-pressure density inferred from shock-wave measurement, which suggests that this phase has the perovskite structure. Gaffney and Ahrens [1969] have recently arrived at a similar conclusion employing a somewhat different approach. (Results on the oxides are summarized in Table 10.)

\section{Behavior of Some Minerals under Shock Compression}

The minerals considered in this section are binary or ternary compounds. The possible transformation modes open to these minerals are broader than those for simple oxides, since in addition to simple transformation into a single isostoichiometric hpp, numerous alternative transformations involving disproportionation into other compounds or even to oxide components are possible.

Spinel, $\mathrm{MgAl}_{2} \mathrm{O}_{4}$, and magnetite, $\mathrm{Fe}^{\prime \prime} \mathrm{Fe}_{2}{ }^{\prime \prime \prime} \mathrm{O}_{4}$. These compounds show clear evidence of transformation to denser phases under shock. The zero-pressure density of the high-pressure spinel phase or phases is $4.19 \mathrm{~g} / \mathrm{cm}^{3}$ (Table 11). It is most significant that this density is $8.5 \%$ higher than the density of a isochemical mixture of $\mathrm{Al}_{2} \mathrm{O}_{3}$ and $\mathrm{MgO}$. These oxides are known to remain stable under high shock pressures. This result strongly indicates that $\mathrm{MgAl}_{2} \mathrm{O}_{4}$ has transformed to a new and homogeneous structural state.

Possible candidates for the inferred high-pressure $\mathrm{MgAl}_{2} \mathrm{O}_{4}$ structures are the closely related $\mathrm{CaFe}_{2}{ }^{\prime \prime \prime} \mathrm{O}_{4}$ and $\mathrm{CaTi}_{2}{ }^{\prime \prime \prime} \mathrm{O}_{4}$ structures [Reid and Ringwood, $1969 b]$. These structures are characteristically displayed by compounds between 
Fig. 13. Ionic radius versus molar volume for oxides that form $\mathrm{AO}_{2}$ compounds in the rutile and/or fluorite structure.

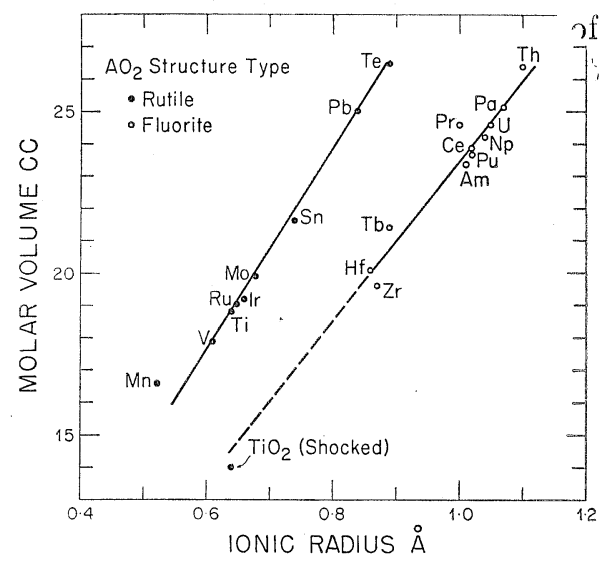

components with rock-salt structures (e.g., $\mathrm{CaO}, \mathrm{SrO}, \mathrm{EuO}$ ) and corundum structures (e.g., $\mathrm{Fe}_{2} \mathrm{O}_{3}, \mathrm{~V}_{2} \mathrm{O}_{3}, \mathrm{Cr}_{2} \mathrm{O}_{3}, \mathrm{Ti}_{2} \mathrm{O}_{3}$ ) [Wyckoff, 1963]. Spinel is likewise a compound formed between the analogous end members $\mathrm{MgO}$ and $\mathrm{Al}_{2} \mathrm{O}_{3}$. The calcium ferrite and calcium titanite structures are characteristically about 4 to $7 \%$ denser than isochemical mixtures of component oxides. Thus, the inferred density of high-pressure $\mathrm{MgAl}_{2} \mathrm{O}_{4}$, although slightly outside this range, is nevertheless in reasonable agreement, considering the uncertainties. In the orthorhombic calcium ferrite structure, the calcium atoms are in eight-fold coordination and the iron atoms are in six-fold coordination, with respect to oxygen.

The inferred zero-pressure density of the hpp magnetite is $6.30 \mathrm{~g} / \mathrm{cm}^{3}$, which is about $21 \%$ denser than magnetite and $15 \%$ denser than an isochemical mixture of $\mathrm{FeO}+\mathrm{Fe}_{2} \mathrm{O}_{3}\left(5.46 \mathrm{~g} / \mathrm{cm}^{3}\right)$. Clearly, a major change has occurred. Crystallographically, it would be reasonable to expect transformation into a calcium ferrite structure, although the density of the new phase appears higher than would be expected for this structure $\left(\sim 5.84 \mathrm{~g} / \mathrm{cm}^{3}\right)$. In view of the various sources of uncertainty, this possibility should not be ruled out. Alternatively, it is possible that magnetite has transformed into an entirely new structure or that it has disproportionated either into $\mathrm{FeO}$ and $\mathrm{Fe}_{2} \mathrm{O}_{3}$ (perovskite ?) ( $\rho=5.94$ $\left.\mathrm{g} / \mathrm{cm}^{3}\right)$ or into $\mathrm{Fe}$ (metal) $+\mathrm{Fe}_{2} \mathrm{O}_{3}$ (perovskite?) $\left(\rho=6.08 \mathrm{~g} / \mathrm{cm}^{3}\right)$, e.g.g

$$
3 \mathrm{Fe}_{3} \mathrm{O}_{4}=\mathrm{Fe}+4 \mathrm{Fe}_{2} \mathrm{O}_{3}
$$

The latter reaction yields the best match, although the density is still somewhat low. (Ringwood and Reid (unpublished) have recently discovered a high-pressure transformation in $\mathrm{Mn}_{3} \mathrm{O}_{4}$, which may be related to the high-pressure $\mathrm{Fe}_{3} \mathrm{O}_{4}$ phase.)

Albite, $\mathrm{NaAlSi}_{3} \mathrm{O}_{8}$; oligoclase, $\mathrm{A}_{81} \mathrm{~A} n_{19}$; and microcline, $\mathrm{KAlSi} i_{3} \mathrm{O}_{8}$. All these minerals show clear evidence of phase transformation under shock. The zeropressure densities of the high-pressure forms of albitite $\left(A b_{88} A n_{12}\right)$, oligoclase $\left(\mathrm{Ab}_{81} \mathrm{An}_{19}\right)$, and microcline are $3.80,3.69$, and $3.51 \mathrm{~g} / \mathrm{cm}^{3}$, respectively, as compared with $2.61,2.63$, and $2.56 \mathrm{~g} / \mathrm{cm}^{3}$ for the natural minerals. These transformations are thus accompanied by large increases in density. 


\section{AHRENS, ANDERSON, AND RINGWOOD}

Ringwood et al. [1967a, b] observed that under static high pressure orthoclase (microcline) transformed to a hollandite structure at a pressure close to $100 \mathrm{~kb}$ at $1000^{\circ} \mathrm{C}$. (They gave $120 \mathrm{~kb}$ as an upper bound for this transformation. Recent work indicates an equilibrium pressure of about $100 \mathrm{~kb}$.) The hollandite form had a density of $3.84 \mathrm{~g} / \mathrm{cm}^{3}$. Further work by the same authors [Reid and Ringwood, 1969c] shows that the feldspars $\mathrm{NaAlGe}_{3} \mathrm{O}_{8}$ and $\mathrm{RbAlGe}_{3} \mathrm{O}_{8}$ also transformed to the hollandite structure, whereas Kume et al. [1966] demonstrated that $\mathrm{KAlGe}_{3} \mathrm{O}_{8}$ feldspar also transforms to the hollandite structure. This mode of transformation is apparently general for alkali feldspars and has also been found in the alkaline earth feldspar, celsian $\left(\mathrm{GaAl}_{2} \mathrm{Si}_{2} \mathrm{O}_{8}\right)$ (unpublished observations, Reid, Wadsley, and Ringwood, 1968).

Although albite disproportionates at relatively low pressures into a mixture of jadeite $+\mathrm{SiO}_{2}$ (quartz, coesite, or stishovite), the above observation strongly suggests that at very high pressure a denser hollandite modification of albite will become stable. The calculated zero-pressure density of the shocked albitite is $3.80 \mathrm{~g} / \mathrm{cm}^{3}$ as compared with approximately $3.85 \mathrm{~g} / \mathrm{cm}^{3}$ for the hollandite structure. The agreement is excellent, and in view of the static high-pressure results for other feldspars, it appears highly probable that albite has indeed transformed to the hollandite structure during the shock. An alternative disproportionation into jadeite + stishovite would yield a density of $3.52 \mathrm{~g} / \mathrm{cm}^{3}$, which is definitely too low. Recently James [1969] has observed a mixture of jadeite and thetomorphic glass in a sodic feldspar that has been intensely shocked from the Ries meteorite crater. Undoubtedly, time effects would be important in this disproportionation reaction.

It also appears probable that oligoclase has also transformed to the hollandite structure; the calculated density $\left(3.59 \mathrm{~g} / \mathrm{cm}^{3}\right)$ is lower and, hence, the jadeite disproportionation reaction cannot be ruled out.

The density of the high-pressure microcline phase was $3.51 \mathrm{~g} / \mathrm{cm}^{3}$ as compared with $3.84 \mathrm{~g} / \mathrm{cm}^{3}$ for the density of $\mathrm{KAlSi}_{3} \mathrm{O}_{8}$ hollandite. Since no other transformation product of orthoclase with a density greater than $3.0 \mathrm{~g} / \mathrm{cm}^{3}$ is known to exist, it appears probable that the microcline transforms to the hollandite structure under shock. The calculated density of the shocked phase is substantially smaller than that of the hollandite structure, although the small number (five) of experimental data points introduces a rather large uncertainty into the calculated density. But when a realistic appraisal of uncertainties is made, the interpretation of the shocked phase as a hollandite is not in conflict with the data. More definitive evidence that microcline and albite transform under shock to phases with the density of hollandite is provided by results on the granite, which are discussed below.

The hollandite structure [Wyckoff, 1963], which is a derivative of the $\alpha \mathrm{MnO}_{2}$ structure, is closely related to the rutile structure. All the aluminum and silicon atoms are octahedrally coordinated. The octahedra are linked by their edges, and the structure possesses holes along the $b$ axis in which the large cations occur. The high density is a result of the octahedral coordination. It is of interest that $\mathrm{KAlSi}_{3} \mathrm{O}_{8}$ hollandite was the second high-pressure phase to be found $\left(\right.$ after $\mathrm{SiO}_{2}$ ) in which all the silicon atoms were octahedrally coordinated. 
Ringwood et al. [1967a] suggested the possibility that natural occurrences of these phases, formed under similar shock conditions to stishovite, may be present in meteorite impact sites.

Twin Sisters dunite, hortonolite dunite, fayalite, and forsterite. Data on the olivine group of minerals are of singular importance to studies of the constitution of the earth's mantle. At pressures near $150 \mathrm{~kb}$ magnesium-rich olivines transform to spinels or spinel-like structures. The densities of these structures are much lower, however, than the inferred densities of the shocked phases, and it appears that the shock transformations overshoot the spinel field.

The Twin Sisters dunite, hortonolite dunite, and fayalite all showed clear evidence of phase transformations under shock. As seen in Table 11, the zeropressure densities of the high-pressure phases are in close agreement with the densities of isochemical mixtures of $\mathrm{MgO}, \mathrm{FeO}$, and $\mathrm{SiO}_{2}$ (stishovite). This might suggest that the olivines have indeed disproportionated into a mixture of oxides during the shock, a view that has been expressed by Birch [1964] and Wang [1967]. That this is possible is demonstrated by results of Ringwood and Reid [1969a], who showed that the spinel $\mathrm{Mg}_{2} \mathrm{SnO}_{4}$ disproportionates into a mixture of $\mathrm{MgO}+\mathrm{SnO}_{2}$ (rutile structure) at high pressures.

An alternative hypothesis would be transformation of the olivines into a new high-pressure phase with $\mathrm{M}_{2} \mathrm{SiO}_{4}$ stoichiometry, which possesses a density similar to that of the mixed oxides. Wadsley et al. [1968] have found that the olivine $\mathrm{Mn}_{2} \mathrm{GeO}_{4}$ transforms at high pressure into the orthorhombic strontium plumbate structure [Trömel, 1965]. This class of structure is characteristically formed between end members possessing rock-salt (e.g., $\mathrm{MnO}, \mathrm{CdO}, \mathrm{CaO}, \mathrm{SrO}$ ) and rutile structures (e.g., $\mathrm{GeO}_{2}, \mathrm{SnO}_{2}, \mathrm{PbO}_{2}$ ). The densities of members of this

TABLE 11. Interpretation of Zero-Pressure Densities and Structures of Some Shocked Minerals

\begin{tabular}{|c|c|c|c|c|c|}
\hline $\begin{array}{l}\text { Initial } \\
\text { Density, } \\
\mathrm{g} / \mathrm{cm}^{3}\end{array}$ & Mineral & $\begin{array}{c}\text { Isochemical } \\
\text { Mixed Oxide } \\
\text { Density, } \\
\mathrm{g} / \mathrm{cm}^{3}\end{array}$ & $\begin{array}{c}\text { Calculated } \\
\text { Zero-Pressure } \\
\text { Density of } \\
\text { Shocked Phases, } \\
\mathrm{g} / \mathrm{cm}^{3}\end{array}$ & $\begin{array}{l}\text { Inferred Structure } \\
\text { of Shocked Phases }\end{array}$ & $\begin{array}{c}\text { Structure } \\
\text { Density, } \\
\mathrm{g} / \mathrm{cm}^{3}\end{array}$ \\
\hline 3.58 & Spinel, $\mathrm{MgAl}_{2} \mathrm{O}_{4}$ & 3.86 & 4.19 & Calcium ferrite & 4.13 \\
\hline 5.20 & Magnetite & 5.54 & 6.30 & $\mathrm{HP} \dagger \mathrm{Fe}_{2} \mathrm{O}_{3}+\mathrm{Fe} ?$ & 6.08 \\
\hline 2.61 & Albite & 3.85 & 3.80 & Hollandite & 3.85 \\
\hline 2.63 & Oligoclase & 3.86 & 3.69 & Hollandite & 3.86 \\
\hline 2.56 & Microcline & 3.86 & 3.51 & Hollandite & 3.84 \\
\hline 3.21 & Forsterite & 3.85 & $4.31 ?^{*}$ & $\mathrm{~K}_{2} \mathrm{NiF}_{4} ?$ & 4.12 \\
\hline 3.32 & Olivine, $\mathrm{Fo}_{90}$ & 4.04 & 4.12 & $\mathrm{Sr}_{2} \mathrm{PbO}_{4}$ & 4.04 \\
\hline 3.72 & Olivine, $\mathrm{Fo}_{45}$ & 4.64 & 4.75 & $\mathrm{Sr}_{2} \mathrm{PbO}_{4}$ & 4.64 \\
\hline 4.39 & Fayalite & 5.29 & 5.31 & $\mathrm{Sr}_{2} \mathrm{PbO}_{4}$ & 5.29 \\
\hline 3.19 & Enstatite & 3.98 & $4.20 ?^{*}$ & Perovskite? & 4.25 \\
\hline 3.27 & Bronzite, $\mathrm{En}_{90}$ & 4.08 & 3.74 & Ilmenite & 3.87 \\
\hline 3.25 & Sillimanite & 4.09 & 4.00 & Corundum + stishovite & 4.09 \\
\hline 3.15 & Andalusite & 4.09 & 3.95 & Cordundum + stishovite & 4.09 \\
\hline
\end{tabular}

* Uncertain value. See text.

$\uparrow$ High pressure. 
class are in close agreement with the mean densities of their isochemical oxide components. Wadsley et al. [1968] have suggested that at high pressures $\mathrm{Mg}_{2} \mathrm{SiO}_{4}$ and $\mathrm{Fe}_{2} \mathrm{SiO}_{4}$ may transform to the strontium plumbate structure. In this class, the divalent atoms are surrounded by six oxygen atoms at the corners of a trigonal prism, whereas the quadrivalent atoms are surrounded octahedrally by six oxygens.

Yet a third possibility is the partial disproportionation of olivines according to

$$
M_{2} \mathrm{SiO}_{4} \text { (olivine, spinel) } \rightarrow M \mathrm{SiO}_{3} \text { (ilmenite) }+M \mathrm{O} \text { (rock salt) }
$$

as suggested by Ringwood [1962b]. Support for this kind of transformation comes from experiments of Akimoto and Syono [1967], who showed that the spinels $\mathrm{Mg}_{2} \mathrm{TiO}_{4}, \mathrm{Fe}_{2} \mathrm{SiO}_{4}$, and $\mathrm{Co}_{2} \mathrm{TiO}_{4}$ transformed in this manner. This transformation would also yield densities close to the densities of the mixed oxides.

Which of the three types of transformations actually occurs under shock conditions will be determined both by kinetic and by thermodynamic factors. As discussed in the introduction, kinetic factors will favor transformation into a homogeneous single phase if a suitable structure exists. The work of Wadsley et al. [1968] indicated that the strontium plumbate is a possible structure with the correct density. Thermodynamic factors are also likely to favor this type of transformation in view of the strong compound-forming tendency of $\mathrm{MgO}$ and $\mathrm{SiO}_{2}$. Further evidence is required, however, before the status of the alternative transformation can be considered firmly established.

The zero-pressure density of the high-pressure phase of the forsterite is $4.31 \mathrm{~g} / \mathrm{cm}^{3}$ as compared with $3.85 \mathrm{~g} / \mathrm{cm}^{3}$ for the isochemical mixture of $\mathrm{MgO}+$ stishovite. This result should be treated with caution, however, since McQueen (personal communication) suggests the possibility of experimental error in the shock data. If confirmed, it would be of considerable importance in further establishing the existence of high-pressure structures that are intrinsically denser than $\mathrm{MgO}-\mathrm{SiO}_{2}$ mixtures. Such structures are also known from static highpressure experiments. Ringwood and Reid [1969b] have reported the transformation of the olivine $\mathrm{Ca}_{2} \mathrm{GeO}_{4}$ to the $\mathrm{K}_{2} \mathrm{NiF}_{4}$ structure at high pressure. This class of structure is often formed from end members possessing rock-salt (e.g., $\mathrm{MgO}$, $\mathrm{CaO}, \mathrm{SrO}, \mathrm{BaO}$ ) and rutile (e.g., $\mathrm{GeO}_{2}, \mathrm{MnO}_{2}, \mathrm{TiO}_{2}, \mathrm{SnO}_{2}, \mathrm{PbO}_{2}, \mathrm{IrO}_{2}, \mathrm{MoO}_{2}$, $\mathrm{RhO}_{2}$ ) structures and the compounds are between 2.2 and $7.3 \%$ denser than the mixed oxides [Wyckoff, 1963].

Bronzitite, enstatite. The bronzitite has a composition $\left(\mathrm{Mg}_{0.9} \mathrm{Fe}_{0.1}\right) \mathrm{SiO}_{3}$ and clearly displays phase transformation under shock. The zero-pressure density of the hpp is estimated to be $3.74 \mathrm{~g} / \mathrm{cm}^{3}$. This value falls within the range of 3.71-3.84 obtained by Wang [1967]. Experimental investigations by Ringwood and Major [1966] and Ringwood [1967] indicate that bronzitite may display at least three modes of transformation at high pressure: to the garnet structure, to the ilmenite structure, or to a mixture of 'spinel' + stishovite. The estimated densities of this phase for the compositions under discussion would be $3.64,3.85$, and $3.77 \mathrm{~g} / \mathrm{cm}^{3}$, respectively. The static high-pressure results indicate that transformation to these phases should occur at pressures between 200 and $300 \mathrm{~kb}$. 
It is not known, however, which particular phase would be formed under equilibrium conditions.

The inferred shock density agrees best with that of an isochemical mixture of 'spinel' + stishovite. (Experiments by Ringwood and Major [1966] showed that the high-pressure form of $\mathrm{Mg}$-rich olivine, although probably related to spinel, is not a true spinel.) Wang [1967] suggested that transformation into this assemblage had occurred during the shock; however, this appears unlikely because in the large amount of information obtained on olivines there is no evidence of transformation to a phase with the density of spinel. It appears that in all cases above about $400 \mathrm{~kb}$ the olivines have transformed into a phase that is much denser than spinel (see previous section). Thus, there is no reason to expect the bronzitite to transform partially to a spinel in a pressure range at which olivines do not display this transformation.

This leaves the garnet and ilmenite structures as possible candidates; the inferred low-pressure denity of the shocked phases is intermediate between these alternatives. The shock data display evidence of an abnormal compressibility, suggesting that complete transformation may not have been obtained. If so, this would imply that the calculated density is on the low side, so that the ilmenite structure would be most probable under shock. Further, the density of the bronzitite at $1000 \mathrm{~kb}$ along the Hugoniot (Table 2) is indeed in close agreement with the probable density of an ilmenite form of bronzite under the same pressure and temperature conditions.

The zero-pressure density of the hpp of pure enstatite is found to be 4.20 $\mathrm{g} / \mathrm{cm}^{3}$ as compared with $3.98 \mathrm{~g} / \mathrm{cm}^{3}$ for an isochemical mixture of $\mathrm{MgO}+\mathrm{SiO}_{2}$ (stishovite). In view of the possibility of experimental error on this specimen (McQueen, personal communication), this result should be treated with caution. Nevertheless, if correct, it is important in further indicating the existence of phases that are denser than the mixed oxides (rock salt and rutile). Ringwood [1966] and Reid and Ringwood [1968] have suggested that $\mathrm{MgSiO}_{3}$ may transform to a perovskite structure at extreme pressures. The density of $\mathrm{MgSiO}_{3}$ in this structure is estimated to be $4.25 \mathrm{~g} / \mathrm{cm}^{3}$, which is in good agreement with the inferred shock density.

The reasons that enstatite and forsterite appear to behave differently under shock than dunite and bronzitite (if indeed this is the case), may be connected either with their iron-free composition or with kinetic factors. Experimental samples of both $\mathrm{MgSiO}_{3}$ and $\mathrm{MgSiO}_{4}$ were somewhat porous, so that they reached substantially higher temperatures than the bronzitite and dunite during the shock. It is conceivable that this could have affected the reaction kinetics, permitting transformation into a denser phase.

Sillimanite and andalusite, $\mathrm{Al}_{2} \mathrm{SiO}_{5}$. Sillimanite and andalusite both display major phase transformations under shock. The zero-pressure densities of these phases are found to be 4.00 and $3.95 \mathrm{~g} / \mathrm{cm}^{3}$, respectively. The close agreement implies that these minerals have probably transformed to the same high-pressure phase or phases. Possible single high-pressure phases are kyanite and also the pseudobrookite structure displayed by $\mathrm{Fe}_{2} \mathrm{TiO}_{5}$ and $\mathrm{Al}_{2} \mathrm{O}_{5}$. The density of kyanite is $3.68 \mathrm{~g} / \mathrm{cm}^{3}$ and the estimated density of $\mathrm{Al}_{2} \mathrm{SiO}_{5}$ in the pseudobrookite struc- 
ture is $3.81 \mathrm{~g} / \mathrm{cm}^{3}$. Both values appear too low to satisfy the shock-wave data, although the pseudobrookite possibility cannot be entirely eliminated.

Although $\mathrm{Al}_{2} \mathrm{GeO}_{5}$ does not exist as a single phase under ambient conditions [Miller et al., 1967], this composition assumes the kyanite structure at $15 \mathrm{~kb}$ and $1700^{\circ} \mathrm{C}$ [Ringwood and Reid, 1969a]. In two runs performed at pressures of 70 $\mathrm{kb}$ and above, complete disproportionation into an oxide mixture of $\mathrm{Al}_{2} \mathrm{O}_{3}$ and $\mathrm{GeO}_{2}$ (rutile) is observed. This suggests the possibility that $\mathrm{Al}_{2} \mathrm{SiO}_{5}$ would transform under pressure to a mixture of $\mathrm{Al}_{2} \mathrm{O}_{3}$ and $\mathrm{SiO}_{2}$. (stishovite) with a mean density of $4.09 \mathrm{~g} / \mathrm{cm}^{3}$. This result is in good agreement with the calculated shock density.

This implies that the kinetic difficulties involved in disproportionation during the sub-microsecond period of a shock pulse may be surmountable. Probably the most important single factor is the availability or non-availability of isochemical compounds of suitable crystal structure and density similar to or greater than those of the mixed oxides into which a given phase may transform.

\section{Shock Transformation in Rocks}

Because of the comparatively large mineral grain size in the rocks investigated ( $>1 \mathrm{~mm}$ on the average) and the short duration of the shock pulse, the possibility of significant reaction between adjacent minerals during the shock may be neglected, and the response of the rock to shock may be discussed in terms of the behavior of the individual minerals.

Westerly granite. This granite is composed principally of quartz $27.5 \%$, microcline $35.4 \%$, oligoclase $\left(\mathrm{An}_{20}\right) 31.4 \%$, and mica $3.2 \%$ [McQueen et al., $1967 b]$. The density of the shocked rock reduced to zero pressure is found to be $3.96 \mathrm{~g} / \mathrm{cm}^{3}$. In the previous sections we concluded that under shock quartz transforms to stishovite and that microcline, albite, and oligoclase transform to the hollandite structure. If we assume that these transformations occurred in the Westerly granite, the theoretical density at low pressure would be $3.97 \mathrm{~g} / \mathrm{cm}^{3}$. This value is in excellent agreement with the calculated density (Table 12) and

TABLE 12. Interpretation of Densities of Shocked Rocks

\begin{tabular}{|c|c|c|c|c|c|}
\hline $\begin{array}{l}\text { Initial } \\
\text { Density, } \\
\mathrm{g} / \mathrm{cm}^{3}\end{array}$ & Rock & $\begin{array}{c}\text { Isochemical } \\
\text { Oxide Density, } \\
\text { g/cm }{ }^{3}\end{array}$ & $\begin{array}{c}\text { Zero-Pressure } \\
\text { Density of } \\
\text { Shocked Phases, } \\
\text { g/ } / \mathrm{cm}^{3}\end{array}$ & $\begin{array}{c}\text { Inferred } \\
\text { Structure } \\
\text { of Shocked } \\
\text { Phases }\end{array}$ & $\begin{array}{l}\text { Structure } \\
\text { Density, } \\
\mathrm{g} / \mathrm{cm}^{3}\end{array}$ \\
\hline 2.63 & Granite & 4.07 & 3.96 & $\begin{array}{l}\text { Stishovite, } \\
\text { hollandites }\end{array}$ & 3.94 \\
\hline 2.75 & Anorthosite & 3.91 & 3.71 & $\begin{array}{l}\text { Hollandite } \\
\quad \text { (pyroxene) }\end{array}$ & 3.85 \\
\hline 2.98 & Diabase & 4.01 & $3.69^{b}$ & $\begin{array}{l}\text { Hollandite } \\
\quad \text { (pyroxene) }\end{array}$ & 3.70 \\
\hline 3.02 & Diabase & 4.08 & $3.68^{b}$ & $\begin{array}{l}\text { Hollandite } \\
\quad \text { (pyroxene) }\end{array}$ & 3.66 \\
\hline
\end{tabular}

a See text.

${ }^{b}$ Anderson and Kanamori [1968]. 
strongly indicates that the interpretation is correct. These observations are particularly important in the case of microcline and imply that the shocked density of this mineral was higher than that calculated on the basis of only five experimental runs on pure microcline specimens as discussed above. Thus, the evidence that microcline actually transforms to the hollandite structure is strongly supported.

Anorthosite. The composition of the anorthosite was $\mathrm{Ab}_{51} \mathrm{An}_{49} \quad(90 \%)$, augite $(10 \%)$. (We will neglect the possible tranformation of augite for reasons discussed in the next section.) The calculated zero-pressure density of the highpressure products of anorthosite is $3.71 \mathrm{~g} / \mathrm{cm}^{3}$. We have already inferred that albite transforms to the hollandite structure above $300 \mathrm{~kb}$, and, in view of the observation that celsian $\mathrm{BaAl}_{2} \mathrm{Si}_{2} \mathrm{O}_{8}$ also transforms to this structure, it is reasonable to expect that anorthosite $\mathrm{CaAl}_{3} \mathrm{Si}_{2} \mathrm{O}_{8}$ behaves likewise at ultrahigh pressures. We would thus expect a solid solution between albite and anorthosite also to transform to isochemical hollandite solid solutions. This structure is very tolerant in its capacity to form solid solutions. The density of the anorthosite in this state would be about $3.9 \mathrm{~g} / \mathrm{cm}^{3}$. This value is in reasonable agreement with the calculated value of $3.71 \mathrm{~g} / \mathrm{cm}^{3}$, considering the uncertainties.

It is also possible to write an equation for the breakdown of albite and anorthite as observed under static conditions between about 30 and $200 \mathrm{~kb}$ :

$$
\text { anorthosite } \begin{aligned}
\left(\mathrm{Ab}_{51} \mathrm{An}_{49}\right) \rightarrow \text { jadeite } & + \text { grossularite }+ \text { kyanite } \\
& +\mathrm{SiO}_{2} \text { (quartz, coesite, stishovite) }
\end{aligned}
$$

The density of the assemblage on the right, if it is assumed that $\mathrm{SiO}_{2}$ is present as stishovite, would be $3.59 \mathrm{~g} / \mathrm{cm}^{3}$, which is slightly closer to the calculated value than the hollandite density. Nevertheless, this alternative does not appear probable because of the kinetic problem involved in decomposing anorthosite into four individual phases, three of which possess complex structures, during the sub-microsecond period of the shock. This type of reaction apparently has occurred in the shocked sodic feldspar of the Ries [James, 1969], except thetomorphic glass, rather than grossularite, kyanite, and stishovite is found with the jadeite. The pressure duration of the Ries event shock was $\sim 10^{4}$ to $10^{6}$ times as long as typical equation of state pressure pulses, and, hence, it is more likely that disproportionation could occur. Also, it should be recalled that, where incomplete transformation occurs, our reduction method yields zero-pressure densities that are too low; it is possible that this factor was involved during the experiments on anorthosite.

Diabases. Anderson and Kanamori [1968] obtained zero-pressure densities of 3.69 and $3.71 \mathrm{~g} / \mathrm{cm}^{3}$ for the W1 and Frederick ( F) diabases respectively. With the techniques described in this paper, these estimates would be raised to about 3.79 and $3.77 \mathrm{~g} / \mathrm{cm}^{3}$. The mineral compositions of these were: for W1 augite, $45 \%$; labradorite, $45 \%$; microcline, $3 \%$; and for Frederick augite, $45 \%$; olivine, $1 \%$; labradorite, $48 \%$; mica, $1 \%$. Comparing with previous results, we might expect that the feldspar would transform to the hollandite structure under shock, whereas the ferromagnesian minerals would transform to phases possessing densities similar to their isochemical mixed oxides. However, the densities to be 
expected on this hypothesis would be close to $4.09 \mathrm{~g} / \mathrm{cm}^{3}$, which is much higher than observed.

An alternative hypothesis would be to suggest that the feldspars transform to the hollandite structure, but the pyroxenes have not transformed at all. On this interpretation, the expected low-pressure densities would be 3.70 (W1) and $3.66(\mathrm{~F}) \mathrm{g} / \mathrm{cm}^{3}$. These values are in satisfactory agreement with the calculated values.

This hypothesis is admittedly of an ad hoc nature and no clear physical explanation for the postulated behavior can be advanced at this stage. There is some support, however, in the observation of rocks that have been strongly shocked during meteoritic impact. In these rocks it is commonly observed that highly compressible minerals, such as feldspars and quartz, have been subjected to major phase transformations, whereas the less compressible ferromagnesian minerals show no evidence of transformation [e.g., Chao, 1967]. If this behavior is maintained under the conditions of the Hugoniot experiments, a simple explanation of the densities of the shocked diabases is available.

\section{SUMMARY AND CONCLUSIONS}

Shock-wave data for rocks and minerals obtained by McQueen and Marsh [1966], McQueen et al. [1967b], Al'tshuler et al. [1965], Trunin et al. [1965], Wackerle [1962], and Ahrens et al. [1969b] have been analyzed to obtain properties of the equation of state and to infer, especially from the zero-pressure density, the crystallography of the high-pressure phase (hpp). With the exception of stishovite $\left(\mathrm{SiO}_{2}\right)$, there is no direct knowledge of the crystallography of the hpp produced in the shock experiments.

The parameters in the Birch-Murnaghan equation were obtained for the twenty-four materials analyzed along the raw Hugoniots centered at zero pressure, the metastable Hugoniots of the shock-induced hpp, and the adiabats and $25^{\circ} \mathrm{C}$ isotherm of the hpp. The available Hugoniot data for most of the rocks and minerals studied may be represented as lying in one or more of the three regimes designated as low-pressure-phase regime, mixed-phase regime, and hpp regime. Of all the minerals and rocks for which data are analyzed, all but three $\left(\mathrm{Al}_{2} \mathrm{O}_{3}\right.$ corundum, $\mathrm{MgO}$ periclase, and $\mathrm{MnO}_{2}$ pyrolusite) appear to have at least one major phase transition between 0 and $800 \mathrm{~kb}$. Because of the marked decreases in volume (typically 20-50\%), the zero-pressure density of the hpp material is a critically important parameter in the analysis of the data. The zero-pressure densities of the hpp's were obtained by restraining the hpp adiabat, calculated from the Hugoniot data, so that the zero-pressure density $\rho_{0}$, zero-pressure seismic parameter $\Phi_{0}$, and mean atomic weight $\bar{M}$ satisfied the equation

$$
\rho_{0} / \bar{M}=0.048 \Phi_{0}{ }^{0.323}
$$

suggested by Anderson [1967]. When this restraint is applied to the shock data for corundum, periclase, pyrolusite, and stishovite, the error in the inferred zeropressure density varies from $-0.8 \%$ for stishovite to $+2.8 \%$ for $\mathrm{MgO}$. The transformation energy $E_{\text {tr }}$ at standard pressure and temperature is also employed in the analysis. In general, transformation energies are estimated from independent thermochemical data for the same or analogous transitions. Uncertainties 
of $\sim 50 \%$ in $E_{\text {tr }}$ result in uncertainties of only $\sim 1 \%$ in the calculated zeropressure densities. The sensitivity of calculated equation of state parameters to assumptions made about both the initial (zero-pressure) value of Grüneisen's ratio $(\gamma)$ and the dependence of $\gamma$ on compression were tested. Since the initial value of $\gamma$ can vary by almost a factor of 2 , depending on whether the Slater or the Dugdale-McDonald value is used, it is found that the assumption of the initial value of $\gamma$ affects the calculated equation of state to a much greater degree than the assumed dependence of $\gamma$ on compression. For example, in $\mathrm{Fe}_{3} \mathrm{O}_{4}$ a change in $\gamma$ from 0.34 to 0.63 (Slater to Dugdale-McDonald) changes the inferred zero-pressure density of the hpp by only $\sim 0.3 \%$ and the zero-pressure bulk modulus by $\sim 1.5 \%$.

The probable crystallography of the oxide and silicate phases produced at high shock pressures is inferred from the calculated zero-pressure density and indirect lines of evidence, such as high-pressure studies of analog systems (e.g., germanates, titanates) under static conditions, as well as the classical rules of crystal chemistry. Except for stishovite, shock recovery experiments have not as yet yielded samples of the hpp's that are actually produced in shock experiments. Statements as to the probable crystallography of the hpp's are therefore necessarily subject to considerable uncertainty. This uncertainty largely depends on the availability of data for appropriate analog systems. The oxides $\mathrm{Al}_{2} \mathrm{O}_{3}$, $\mathrm{MgO}$, and $\mathrm{MnO}_{2}$ do not appear to have significant phase transitions up to $\sim 1200 \mathrm{~kb}$. Rutile $\left(\mathrm{TiO}_{2}\right)$ appears to transform from an initial density of 4.25 $\mathrm{g} / \mathrm{cm}^{3}$ to a hpp with a zero-pressure density of $5.71 \mathrm{~g} / \mathrm{cm}^{3}$. As previously inferred by $M c Q u e e n$ et al. [1967a], this hpp probably has the fluorite structure. Although similar transformations are known to occur in $\mathrm{PbO}_{2}$, the analogous transformations are not detected in the analysis of the $\mathrm{SiO}_{2}$ shock data (available to 2000 $\mathrm{kb}$ and presumably representing stishovite above $\sim 400 \mathrm{~kb}$ ). The hpp of hematite $\left(\mathrm{Fe}_{2} \mathrm{O}_{3}\right)$, density 5.96 , versus $5.27 \mathrm{~g} / \mathrm{cm}^{3}$ for the low-pressure phase, is inferred by Reid and Ringwood [1969a] to have the perovskite structure, although the $\mathrm{B}$ rare earth structure $\left(\mathrm{Sc}_{2} \mathrm{O}_{3}\right)$ is another possibility. Spinel, $\mathrm{MgAl}_{2} \mathrm{O}_{4}$, transforms to a phase that has zero-pressure density of $4.19 \mathrm{~g} / \mathrm{cm}^{3}$, which compares with a density of $3.86 \mathrm{~g} / \mathrm{cm}^{3}$ for the isochemical mixed oxides. Reid and Ringwood [1969b] infer that the structure for this phase may be similar to that of $\mathrm{CaFe}_{2} \mathrm{O}_{4}$. The hpp of magnetite $\left(\mathrm{Fe}_{3} \mathrm{O}_{4}\right)$ has a density of 5.54 as compared with 5.20 $\mathrm{g} / \mathrm{cm}^{3}$ for the low-pressure phase. This phase may represent either a disproportionated product of $\mathrm{FeO}+\mathrm{Fe}_{2} \mathrm{O}_{3}$ (perovskite) or possibly the orthorhombic $\mathrm{CaFe}_{2} \mathrm{O}_{4}$ structure.

The minerals albite, oligoclase, and microcline all appear to transform to the hollandite structure, density $\sim 3.85 \mathrm{~g} / \mathrm{cm}^{3}$ [Ringwood et al., 1967a, b]. Either this transformation is not completed over the range of data in the pure mineral samples, or a disproportionation reaction similar to that which forms jadeite, grossularite, kyanite, and stishovite takes place. The zero-pressure densities of the high-pressure products of Westerly granite $\left(3.96 \mathrm{~g} / \mathrm{cm}^{3}\right)$ and anorthosite $\left(3.71 \mathrm{~g} / \mathrm{cm}^{3}\right)$ are consistent with the density of a mixture of stishovite and feldspar (in the hollandite structure) existing at high pressure.

For olivines, since the hpp zero-pressure density is typically about $20 \%$ 
higher than the starting niaterial, the olivine-spinel transition (usually involving a density increase of less than 10\%) is clearly overdriven. Although the hpp densities are close to the densities that would occur if this mineral were to disproportionate either to the oxides periclase, wüstite, and stishovite or to ilmenite and rock-salt structure in the range $\mathrm{Fo}_{90}$ to $\mathrm{Fo}_{10}$, it appears most likely that the $\mathrm{Sr}_{2} \mathrm{PbO}_{4}$ structure [Wadsley et al., 1968] is produced. In the case of pure forsterite, with an initial density of $3.21 \mathrm{~g} / \mathrm{cm}^{3}$, a hpp material having a density of $4.31 \mathrm{~g} / \mathrm{cm}^{3}$ is obtained. This value compares with $4.12 \mathrm{~g} / \mathrm{cm}^{3}$ for the hpp of Twin Sisters dunite $\left(\mathrm{F}_{\mathrm{g}_{0}}\right)$. A somewhat higher density of the magnesia end member may represent the formation of the $\mathrm{K}_{2} \mathrm{NiF}_{4}$ structure rather than the $\mathrm{Sr}_{2} \mathrm{PbO}_{4}$ structure. The $\mathrm{K}_{2} \mathrm{NiF}_{4}$ structure is taken by the olivine $\mathrm{Ca}_{2} \mathrm{GeO}_{4}$ [Ringwood and Reid, 1969b]. This result should, however, be taken with caution as only a few less reliable Hugoniot points are reported for this material.

The Hugoniot data for bronzitite $\left(\mathrm{En}_{90}\right)$ give a hpp zero-pressure density of $3.74 \mathrm{~g} / \mathrm{cm}^{3}$ as compared with a starting density of $3.27 \mathrm{~g} / \mathrm{cm}^{3}$. The hpp is thought to represent most probably an ilmenite structure. The relatively low zero-pressure bulk modulus inferred for the hpp material $(\sim 2100 \mathrm{~kb})$ suggests that the experimental data may not all lie within the high-pressure phase regime.

As in the case of pure forsterite, the data for pure enstatite are also less reliable. They also give significantly higher densities than the material containing more $\mathrm{FeO}$. The inferred zero-pressure density of the hpp, $4.20 \mathrm{~g} / \mathrm{cm}^{3}$, correlates well with the expected zero-pressure density of $4.25 \mathrm{~g} / \mathrm{cm}^{3}$ for the perovskite structure.

Sillimanite and andalusite have hpp zero-pressure densities of 4.00 and 3.95 $\mathrm{g} / \mathrm{cm}^{3}$. These values probably represent the disproportionation reaction products $\mathrm{Al}_{2} \mathrm{O}_{3}$ and $\mathrm{SiO}_{2}$ (stishovite). This mixture would have a theoretical zero-pressure density of $4.09 \mathrm{~g} / \mathrm{cm}^{3}$.

The equation of state parameters of the hpp's display several trends that are significant with regard to the constitution and equation of state of the earth's lower mantle. We find that the second-order parameter $\xi$ in the Birch-Murnaghan equation

$$
P=\left(3 K_{0} / 2\right)\left[\left(\rho / \rho_{0}\right)^{7 / 3}-\left(\rho / \rho_{0}\right)^{5 / 3}\right]\left\{1-\xi\left[\left(\rho / \rho_{0}\right)^{2 / 3}-1\right]\right\}
$$

is nearly zero for the oxides $\mathrm{MgO}$ and $\mathrm{Al}_{2} \mathrm{O}_{3}$. For stishovite, we find $\xi=0.73$ and $K_{o s}{ }^{\prime}=(d K / d P)_{s}=3$ (a later analysis yields a value of $K_{o s}{ }^{\prime}$ of 7 [Ahrens et al., 1969b]), whereas for the hpp of olivines and pyroxenes values of $\xi$ closer to 1 with values of $K_{0 s}{ }^{\prime}$ of 2 to 3 are obtained. The value of $d K / d P$ calculated along the adiabat and Hugoniot curves (the Hugoniot representing higher temperatures) decreases with increasing compression. The rate of decrease of $K^{\prime}$ with density inferred from the Birch-Murnaghan equation is similar for all the oxides and hpp's of the silicates. These values vary from -0.5 to $-0.7 \mathrm{~cm}^{3} / \mathrm{g}$. Increasing the density on substitution of $\mathrm{FeO}$ for $\mathrm{MgO}$ gives values for the change of $(d K / d P)$ with density in the range -0.3 to $-1.6 \mathrm{~cm}^{3} / \mathrm{g}$. The values of $\gamma$ for the hpp's are between 0.5 and 1.0 and are related to $K_{0 t}{ }^{\prime}$; which is also generally lower for the hpp's and decreases with compression and increasing iron content.

Since the Hugoniot data for $\mathrm{MgO}$ and $\mathrm{Al}_{2} \mathrm{O}_{3}$ indicate that no significant 
phase transition has taken place in these materials, the zero-pressure densities were constrained to their zero-pressure values for the purpose of further analysis. The resulting bulk moduli obtained were higher than the ultrasonic values of 1622 and $2521 \mathrm{~kb}$. Since no internal rearrangement takes place at the shock front (presumably because of the lack of a phase transition), strength effects will produce a Hugoniot curve for $\mathrm{MgO}, \mathrm{Al}_{2} \mathrm{O}_{3}$, and $\mathrm{MnO}_{2}$, which is offset in shock stress above the hydrostatic curve. After correcting the raw Hugoniot data for $\mathrm{MgO}$ and ceramic and crystalline $\mathrm{Al}_{2} \mathrm{O}_{3}$ for residual strength effects (by relating the net shear stress at high-shock pressures to the stress existing at the Hugoniot elastic limit [Ahrens et al., 1968]), an analysis of the hydrostatic Hugoniot was performed. A corrected Hugoniot yields values for the zero-pressure adiabatic bulk modulus of 1675,2563 , and $2919 \mathrm{~kb}$ for $\mathrm{MgO}$ and ceramic and crystalline $\mathrm{Al}_{2} \mathrm{O}_{3}$. These values are in good agreement with the ultrasonic data. The good agreement in both bulk moduli and $\left(d K_{0 s} / d P\right)_{s}$ is consistent with the result that $\mathrm{MgO}$ and $\mathrm{Al}_{2} \mathrm{O}_{3}$ do not undergo phase changes over the range of the shock data and, furthermore, that these materials support significant levels of shear stress above shock pressures of 150 and $300 \mathrm{~kb}$, respectively. In the case of $\mathrm{MgO}$ the latter conclusion depends strongly on the validity of the Birch-Murnaghan form of the equation of state to $\sim 1.2 \mathrm{Mb}$.

Acknowledgments. We appreciate receiving copies of papers prior to publication from N. Mao, O. Anderson, E. Schreiber, D. Chung, and N. Soga.

This research was supported in part by the Defense Atomic Support Agency under contract DASA 01-06-C-0069

\section{REFERENCES}

Ahrens, T. J., High-pressure electrical behavior and equation of state of magnesium oxide from shock wave measurements, J. Appl. Phys., 37, 2530, 1966.

Ahrens, T. J., W. H. Gust, and E. B. Royce, Material strength effect in the shock compression of alumina, J. Appl. Phys., 39, 4610-4616, 1968.

Ahrens, T. J., and R. L. Linde, Response of brittle solids to shock compression, Proc. Intern. Union Theoret. Appl. Mechanics Symposium, The Behavior of Dense Media under High Dynamic Pressures, Paris, Sept. 11-15, Gordon and Breach, New York and Paris, 1967.

Ahrens, T. J., C. F. Petersen, and J. F. Rosenberg, Shock compression of feldspars, J. Geophys. Res., 74, 2727-2746, 1969a.

Ahrens, T. J., T. Takahashi, and G. Davies, A proposed equation of state of stishovite, to be published, 1969b. (Will appear in J. Geophys. Res., 75(2), 1970.)

Akimoto, S., and Y. Syono, High-pressure decomposition of some titanate spinels, J. Chem. Phys., 47, 1813, 1967.

Alder, B., Is the mantle soluble in the core?, J. Geophys. Res., 71, 4973, 1966.

Al'tshuler, L. V., R. F. Trunin, and G. V. Simakov, Shock-wave compression of periclase and quartz and the composition of the earth's lower mantle, Bull. Acad. Sci. USSR, no. 10, 657, 1965.

Anderson, Don L., A seismic equation of state, Geophys. J., 13, 9, 1967.

Anderson, Don L., Bulk modulus-density systematics, J. Geophys. Res., 74, 3857-3864, 1969.

Anderson, Don L., and H. Kanamori, Shock-wave equations of state for rocks and minerals, J. Geophys. Res., 20, 6477-6502, 1968.

Anderson, O. L., Determination and some uses of isotropic elastic constants of polycrystalline aggregates using single crystal data, Phys. Acoust., 3B, 43, 1965 a.

Anderson, O. L., Two methods of estimating compression and sound velocity at very high pressures, Proc. Nat. Acad. Sci. U. S., 54, 667, $1965 b$. 
Anderson, O. L., Some remarks on the volume dependence of the Grüneisen parameter, $J$. Geophys. Res., 16, 5187-5194, 1968.

Anderson, O. L., E. Schreicher, R. Liebermann, and N. Soga, Some elastic constant data on minerals relevant to geophysics, Rev. Geophys., 6, 491-524, 1968.

Birch, F., Elasticity and constitution of the earth's interior, J. Geophys. Res., 57, 227, 1952.

Birch, F., The velocity of compressional waves in rocks to 10 kilobars, 2, J. Geophys. Res., $66,2199-2224,1961$.

Birch, F., Density and composition of mantle and core, J. Geophys. Res., 69, 4377, 1964.

Chao, E., Impact metamorphism, in Researches in Geochemistry, vol. 2, pp. 204-233, John Wiley, New York, 1967.

Chung, D., First pressure derivatives of polycrystalline elastic moduli: Their relation to single-crystal acoustic data and thermodynamic relations, J. Appl. Phys., 38, 5104, 1967.

Clendenen, R. L., and H. G. Drickamer, Lattice parameters of nine oxides and sulphides as a function of pressure, J. Chem. Phys., 44, 4223, 1966.

DeCarli, P. S., and D. J. Milton, Stishovite: Synthesis by shock wave, Science, 147, 144, 1965.

Fujisawa, H., Temperature and discontinuities in the transition layer in the earth's mantle: Geophysical application of the olivine spinel transition in the $\mathrm{Mg}_{2} \mathrm{SiO}_{4}-\mathrm{Fe}_{2} \mathrm{SiO}_{4}$ system, J. Geophys. Res., 78, 3281, 1968.

Fyfe, W. S., Stability of $\mathrm{Al}_{2} \mathrm{SiO}_{5}$ polymorphs, Chem. Geol., 2, 67-76, 1967.

Gaffney, E. S., and T. J. Ahrens, Stability of mantle minerals from lattice calculations and shock wave data, Phys. Earth Planet. Interiors, 5, in press, 1969.

Goldschmidt, V. M., Zur Kirstallchemie des Germaniums, Nachr. Akad. Wiss. Goettingen, Math. Physik. Kl. 11a, 2, 184, 1931.

Holm, J. L., O. J. Kleppa, and E. F. Westrum, Jr., Thermodynamics of polymorphic transformations in silica. Thermal properties from $5^{\circ}$ to $1070^{\circ} \mathrm{K}$ and pressure-temperature stability fields for coesite and stishovite, Geochim. Cosmochim. Acta, 31, 2289, 1967.

James, O. B., Jadeite: Shock-induced formation from oligoclase, Ries Crater, Germany, Science, 165, 1005, 1969.

Jones, A. A., W. M. Isbell, F. H. Shipman, R. D. Perkins, S. J. Green, and C. J. Maiden, Material property measurements for selected materials, General Motors Materials and Structures Lab. Rep., NAS2-3427, 1968.

Knopoff, L., Approximate compressibilities of elements and compounds, Phys. Rev., 138, A1445, 1965.

Kume, S., T. Matsumoto, and M. Koizumi, Dense form of germanate orthoclase $\left(\mathrm{KAlGe}_{5} \mathrm{O}_{8}\right)$, J. Geophys. Res., 71, 4999, 1966.

McQueen, R. G., J. N. Fritz, and S. P. Marsh, On the equation of state of stishovite, J. Geophys. Res., 68, 2319, 1963.

McQueen, R. G., J. C. Jamieson, and S. P. Marsh, Shock wave compression and X ray studies of titanium dioxide, Science, 155, 1401, 1967a.

McQueen, R. G., and H. M. Marsh, in Handbook of Physical Constants, edited by S. P. Clark, Jr., Memoir 97, Geological Society of America, New York, 1966.

McQueen, R. G., S. P. Marsh, and J. N. Fritz, Hugoniot equation of state of twelve rocks, J. Geophys. Res., 72, 4999, $1967 b$.

Miller, J. L., Jr., G. R. McCormick, and S. G. Ampian, Phase equilibrium in the system $\mathrm{GeO}_{2}-\mathrm{Al}_{2} \mathrm{O}_{3}$, J. Amer. Ceram., 50, 268-269, 1967.

Murnaghan, F. D., Compressibility of media under extreme pressure, Proc. Nat. Acad. Sci. U. S., 30, 244, 1944.

Pastine, D. J., and D. Piacesi, The existence and implications of curvature in the relation between shock and particle for metals, J. Phys. Chem. Solids, 27, 1783-1797, 1966.

Perez-Albuerne, E. A., and H. G. Drickamer, Effect of high pressures on the compressibilities of seven crystals having the $\mathrm{NaCl}$ or $\mathrm{CsCl}$ structure, J. Chem. Phys., 43, 1381, 1965.

Reid, A. F., and A. E. Ringwood, High-pressure scandium oxide and its place in the molar volume relationships of dense structures of $M_{2} X_{3}$ and $A B X_{3}$ type, J. Geophys. Res., 74, 3238-3252, 1969a.

Reid, A. F., and A. E. Ringwood, High-pressure $\mathrm{Mn}_{3} \mathrm{O}_{4}$, an isomorph of $\mathrm{Ca}_{2} \mathrm{Mn}_{2} \mathrm{O}_{4}$ and an 
example of the structure classes appropriate to dense spinel polymorphs, in preparation, $1969 b$.

Reid, A. F., and A. E. Ringwood, Six-coordinate silicon: High-pressure strontium and barium aluminosilicates with the hollandite structure, J. Solid State Chem., in press, $1969 c$.

Rice, M. H., R. G. McQueen, and J. M. Walsh, Compression of solids by strong shock waves, in Solid-State Physics, vol. 6, edited by F. Seitz and D. Turnbull, pp. 1-63, Academic, New York, 1958.

Ringwood, A. E., Prediction and confirmation of olivine-spinel transition in $\mathrm{Ni}_{2} \mathrm{SiO}_{4}$, Geochim. Cosmochim. Acta, 26, 451, 1962a.

Ringwood, A. E., Mineralogical constitution of the deep mantle, J. Geophys. Res., 67, $4005,1962 b$.

Ringwood, A. E., Mineralogy of the mantle, in Advances in Earth Science, edited by P. M. Hurley, pp. 357-359, M.I.T. Press, Cambridge, Mass., 1966.

Ringwood, A. E., The pyroxene garnet transformation in the earth's mantle, Earth Planet. Sci. Lett., 2, 255, 1967.

Ringwood, A. E., and A. Major, Synthesis of $\mathrm{Mg}_{2} \mathrm{SiO}_{4}-\mathrm{Fe}_{2} \mathrm{SiO}_{4}$ spinel solid solutions, Earth Planet. Sci. Lett., 1, 241, 1966.

Ringwood, A. E., and A. Major, High pressure transformations in pyroxenes, Earth Planet. Sci. Lett., 1, 351, 1967.

Ringwood, A. E., and A. F. Reid, High pressure transformation of spinels, 1, Earth Planet. Sci. Lett., in press, 1969 .

Ringwood, A. E., and A. F. Reid, High pressure polymorphs of olivines: The $\mathrm{K}_{2} \mathrm{NiF}_{4}$ type, Earth Planet, Sci. Lett., in press, $1969 b$.

Ringwood, A. E., A. F. Reid, and A. D. Wadsley, High-pressure $\mathrm{KAlSi}_{3} \mathrm{O}_{8}$, an aluminosilicate with sixfold coordination, Acta Cryst., 23, 1093, $1967 a$.

Ringwood, A. E., A. F. Reid, and A. D. Wadsley, High pressure transformation of alkali aluminosilicates and aluminogermanates, Earth Planet. Sci. Lett. 3, 38, $1967 b$.

Ringwood, A. E., and M. Seabrook, Olivine-spinel equilibria at high pressure in the system $\mathrm{Ni}_{2} \mathrm{GeO}_{4}-\mathrm{Mg}_{2} \mathrm{SiO}_{4}$, J. Geophys. Res., 67, 1975, 1962.

Ringwood, A. E., and M. Seabrook, High-pressure transformations in germanate pyroxenes and related compounds, J. Geophys. Res., 68, 4601, 1963.

Ruoff, A. L., Linear shock-velocity-particle-velocity relationship, J. Appl. Phys., 38, 4976, 1967.

Stishov, S. M., and S. V. Popova, A new dense modification of silica, Geokhimiyi, no. 10, 837, 1961.

Syono, Y., and S. Akimoto, High pressure synthesis of fluorite-type $\mathrm{PbO}_{2}$, Material Research Bulletin, 8, no. 2, 1968.

Thompsen, L., On the fourth order anharmonic equation of state of solids, to be published, 1969.

Trömel, M., Zur Struktur der Verbindungen vom $\mathrm{Sr}_{2} \mathrm{PbO}_{4}$-Typ, Naturwiss. 17, 492-493, 1965.

Trunin, R. F., V. I. Gon'shakova, G. V. Simakov, and N. E. Galdin, A study of rocks under the high pressures and temperatures created by shock compression, (in Russian), Izv. Acad. Sci., USSR, Phys. Solid Earth, no. 9, 1-12, 1965. Also Engl. Transl., no. 9, 579-586, 1966.

Wackerle, J., Shock-wave compression of quartz, J. Appl. Phys., 33, 922, 1962.

Wadsley, A. D., A. F. Reid, and A. E. Ringwood, The high pressure form of $\mathrm{Mn}_{2} \mathrm{GeO}_{4}$, a member of the olivine group. Acta Cryst., B24, 740-742, 1968.

Walsh, J. M., and R. H. Christian, Equations of state of metals from shock wave measurements, Phys. Rev., 97, 1544, 1955.

Wang, C., Phase transitions in rocks under shock compression, Earth Planet. Sci. Lett., 3, $107,1967$.

Wang, C., Equation of state of periclase and Birch's relationship between velocity and density, Nature, 218, 74, 1968.

Wyckoff, R. W. G., Crystal Structures, vol. 1, 2, and 3, 2nd edition, Interscience, New York, 1963. 